\title{
Model Analysis of the Effects of Active Phase Distribution at the Pellet Scale in Catalytic Reactors for the Direct Dimethyl Ether Synthesis
}

\author{
Simone Guffanti, Carlo Giorgio Visconti, and Gianpiero Groppi*
}

Cite This: Ind. Eng. Chem. Res. 2020, 59, 14252-14266

Read Online

ACCESS | Lill Metrics \& More | 国 Article Recommendations | (1) Supporting Information

ABSTRACT: The direct synthesis of dimethyl ether (DME) from syngas is an exothermic process, which requires two different catalyst functions in the same reactor: methanol $(\mathrm{MeOH})$ synthesis and dehydration to DME. The two functions can be intimately mixed in hybrid pellets, located on separated pellets or coupled in core@shell-engineered pellets. In this work, a multitubular fixedbed reactor, loaded with the catalyst configurations mentioned above, has been investigated by mathematical modeling. It is shown that the different spatial distribution of the active phases has a drastic impact on reactor performance. Using the mechanical
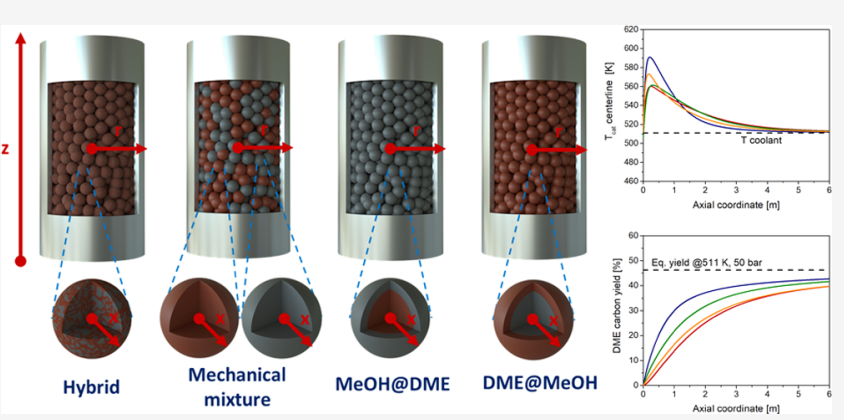
mixture of separated pellets, the DME yield is hindered by intraparticle diffusion limitations. The hybrid catalyst, minimizing the diffusion length between methanol synthesis and dehydration catalyst functions, provides better DME yield performances but higher hotspot temperatures and can suffer from deactivation issues due to the detrimental interaction between the two catalytic functions. The MeOH@DME configuration, which allows for a limited contact between the catalyst active phases, guarantees DME yields comparable to those of hybrid pellets while moderating the hotspot temperature.

\section{INTRODUCTION}

Dimethyl ether (DME) is a commodity mainly employed as a propellant for aerosol spray, a solvent, and a refrigerant due to its relatively low ozone depletion potential (ODP) and global warming potential (GWP). ${ }^{1}$ In the past decades, there has been a growing interest in the production of DME for energetic uses: DME is indeed a possible substitute for liquid petroleum gas (LPG) in domestic and industrial applications due to the similar physical properties, ${ }^{2-5}$ while the high cetane number, low $\mathrm{CO}_{2}$ emission, and the low $\mathrm{NO}_{x}$ and particulate formation during combustion make it a promising clean fuel for compression diesel engines. ${ }^{2,3,6,7}$ DME can be also employed as a hydrogen carrier by reforming in fuel cells, $^{2,3,8-10}$ as fuel for power generation,,$^{2,3,11,12}$ and as a feedstock in the production of olefins ${ }^{13,14}$ and gasoline.

Starting from syngas, DME can be produced through two possible routes: a two-step process (indirect synthesis) consisting of methanol $(\mathrm{MeOH})$ synthesis followed by methanol dehydration to DME or a one-step process (direct synthesis) in which DME is directly obtained from syngas in a single reactor. ${ }^{15}$ The reactions involved in this latter process are the methanol synthesis from $\mathrm{CO}$ and $\mathrm{CO}_{2}$ (reactions 1 and 2), water-gas shift (WGS) (reaction 3), and methanol dehydration to DME (reaction 4)

$$
\mathrm{CO}+2 \mathrm{H}_{2} \leftrightarrow \mathrm{CH}_{3} \mathrm{OH}, \quad \Delta H_{\mathrm{r}}^{0}=-90.5 \mathrm{~kJ} / \mathrm{mol}
$$

$$
\begin{aligned}
& \mathrm{CO}_{2}+3 \mathrm{H}_{2} \leftrightarrow \mathrm{CH}_{3} \mathrm{OH}+\mathrm{H}_{2} \mathrm{O}, \quad \Delta H_{\mathrm{r}}^{0}=-49.4 \mathrm{~kJ} / \mathrm{mol} \\
& \mathrm{CO}+\mathrm{H}_{2} \mathrm{O} \leftrightarrow \mathrm{CO}_{2}+\mathrm{H}_{2}, \quad \Delta H_{\mathrm{r}}^{0}=-41.1 \mathrm{~kJ} / \mathrm{mol} \\
& 2 \mathrm{CH}_{3} \mathrm{OH} \leftrightarrow \mathrm{CH}_{3} \mathrm{OCH}_{3}+\mathrm{H}_{2} \mathrm{O}, \Delta H_{\mathrm{r}}^{0}=-23.0 \mathrm{~kJ} / \mathrm{mol}
\end{aligned}
$$

The main reason for coupling the methanol synthesis and dehydration reactions in the direct DME synthesis is the beneficial effect on the reaction thermodynamic equilibria: ${ }^{16-18}$ methanol produced by 1 and 2 is consumed by 4 to form DME; meanwhile, water produced in 2 and 4 is consumed by WGS (3). This potentially leads to higher syngas per pass conversion and DME yield with respect to the indirect synthesis.

Two main issues are related however to the direct DME synthesis: the catalyst design ${ }^{15,19}$ and the thermal management of the reactor. ${ }^{20-22}$ The catalyst design is challenging because

Received: April 16, 2020

Revised: July 13, 2020

Accepted: July 19, 2020

Published: July 19, 2020

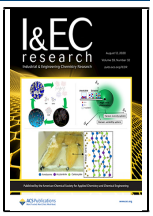


two different catalytic functions are coupled in the same reactor: a metallic function for the hydrogenation of $\mathrm{CO}_{x}$ to methanol (reactions 1 and 2), which is typically associated with the well-established commercial $\mathrm{Cu} / \mathrm{ZnO} / \mathrm{Al}_{2} \mathrm{O}_{3}$ (CZA), ${ }^{23}$ and an acidic function for the dehydration of methanol to DME (reaction 4), typically activated on $\mathrm{Al}_{2} \mathrm{O}_{3}$ or zeolites. ${ }^{24}$ The two functions can be intimately coupled in a hybrid catalyst obtained either by mixing and pelletizing fine powders of the two formulations or by synthetizing the bifunctional material by coprecipitation or impregnation. ${ }^{19,25}$ The hybrid configuration is reported as the most efficient, thanks to the close contact between the methanol synthesis and methanol dehydration active sites. ${ }^{21}$ However, hybrid catalysts can suffer from deactivation due to (i) the migration of $\mathrm{Cu}$ and $\mathrm{Zn}$ to the acidic sites, ${ }^{26,27}$ (ii) the migration of Si to the CZA catalyst, ${ }^{27}$ (iii) the pore blockage caused by carbonaceous species deposition, ${ }^{28,29}$ or (iv) the sintering of $\mathrm{Cu}$ nanoclusters due to the interaction of aluminosilicates and $\mathrm{Cu}$ sites. $^{28-32}$

The simplest way to avoid these issues consists of minimizing the contact between the metallic and acidic active phases, thus reducing their detrimental interactions, by loading in the reactor-separated pellets for methanol synthesis and methanol dehydration (configuration referred to as "mechanical mixture" in the following). The mechanical mixture configuration is anyway recognized as less efficient: the active phases for methanol synthesis and dehydration are not in close contact, with a partial loss of the synergistic effect due to mass transport limitations. ${ }^{21}$

The use of structured patterns of active phase distribution within a catalyst pellet has been considered for many decades as a promising tool for optimization of reactor performances. ${ }^{33}$ In the specific case of DME direct synthesis, core-shell (core@shell) catalysts ${ }^{34-44}$ have been recently proposed as a tradeoff between the hybrid configuration and the mechanical mixture configuration. Both the configuration with DME synthesis function in the core and methanol synthesis function in the shell (DME@MeOH $)^{36}$ and the reverse one with the methanol catalyst in the core and the DME catalyst in the shell (MeOH@DME) $)^{34,35,37-44}$ have been synthetized and tested. It has been shown that core@shell catalysts suffer less than hybrid pellets from issues related to catalyst deactivation, ${ }^{43}$ while keeping a good synergy between methanol synthesis and methanol dehydration functionalities. Moreover, in the core@ shell configuration, an intermediate inactive layer can be used to avoid the direct contact between the two active phases with consequent deactivation. ${ }^{35}$

Thermal management of the reactors, as previously stated, represents another major issue in direct DME synthesis as a consequence of the strong exothermicity of the process. All of the reactions $1-4$ are indeed exothermic. To carefully control the catalyst temperature, externally cooled multitubular fixedbed reactors, ${ }^{20-22,45-47}$ slurry-phase reactors, ${ }^{4-51}$ fluidizedbed reactors, ${ }^{52}$ and micropacked bed reactors ${ }^{53-56}$ have been tested. Fixed-bed reactors are preferred at the industrial scale for their simplicity and lower capital costs. ${ }^{15}$

Fixed-bed reactors have been modeled for simulation and design purposes by means of (i) single-tube, one-dimensional (1D), pseudohomogeneous models; ${ }^{18,45}$ (ii) $1 \mathrm{D}+1 \mathrm{D}$ heterogeneous models, ${ }^{20-22}$ which also account for the concentration gradients inside the catalyst pellets; and (iii) two-dimensional (2D) heterogeneous models, ${ }^{47}$ which also describe the radial gradients within the reactor tubes. In particular, industrial-scale reactor configurations with hybrid pellets and a mechanical mixture of $\mathrm{MeOH}$ and DME catalysts have been comparatively investigated by a $1 \mathrm{D}+1 \mathrm{D}$ model. $^{20,21}$ Notably, modeling studies considering the core@shell configurations in large-scale reactors are not available in the open literature to our knowledge. Besides, experimental studies $^{34-44}$ have been performed with small-size particles (0.06-1.7 mm), which minimize intraporous diffusional effects but cannot be directly scaled up to industrial configurations, where pressure drops become an issue and pellets of millimeter size must be adopted.

To fill this gap and to quantitatively address the effects of different active phase distributions, hybrid pellets, mechanical mixtures of methanol synthesis and methanol dehydration pellets, and $\mathrm{MeOH} @ \mathrm{DME}$ and DME@MeOH core@shell configurations are comparatively analyzed in this work by means of $2 \mathrm{D}+1 \mathrm{D}$ heterogeneous models of a single tube of an externally cooled multitubular fixed-bed industrial reactor for direct DME synthesis. Industrial benchmark catalyst formulations are considered; i.e., CZA for methanol synthesis and $\gamma$ alumina for methanol dehydration. The results are interpreted through the detailed analysis of the reaction-diffusion phenomena inside the catalyst pellets, highlighting the impact of the active phase distribution on the DME yield and on the thermal behavior of the fixed-bed reactor and pointing out the potential advantages of using core@shell pellets.

\section{METHODS}

2.1. Reactor Model. A heterogeneous model of one single tube of an externally cooled multitubular fixed-bed reactor for the direct DME synthesis has been developed. The model consists of $i$-species mass and energy $2 \mathrm{D}$ balances for the gas phase, coupled with gas-solid continuity equations and 1D $i$ species mass balance in isothermal spherical pellets. A 1D momentum balance has been also implemented to evaluate pressure drops along the tubes. The balance equations together with kinetic expressions and correlations to estimate physicochemical and transport properties have been implemented in gPROMS commercial software for the numerical solution of the boundary values problem.

Some differences in model equations exist for the various catalyst configurations (mechanical mixture, hybrid, and core@ shell pellets), which are mostly related to the description of internal concentration profiles in the catalyst. Accordingly, the $1 \mathrm{D}$ mass balance of isothermal pellets is first described in the following.

2.2. 1D Pellet Mass Balance. The mass balances in the solid phase consider the interaction between reaction and diffusion phenomena inside spherical catalyst pellets. A Fickian diffusion model is employed in the analysis; this choice has been validated by comparison with a more rigorous dusty-gas model based on Maxwell-Stefan diffusion equations ${ }^{57-61}$ (reported in Supporting Information S4).

Two separate mass balances for the $i$-species (5) are present in mechanical mixture configuration, one for each $k$-catalyst function $(\mathrm{MeOH}$ or DME catalyst)

$$
\begin{aligned}
& \frac{1}{x^{2}} \frac{\partial}{\partial x}\left(x^{2} D_{\mathrm{eff}, i} \rho_{g} \frac{\partial \omega_{\mathrm{s}, i, k}}{\partial x}\right)+\mathrm{MW}_{i} \rho_{\mathrm{s}, k} \sum_{j=1}^{\mathrm{NR}} \nu_{i j} R_{j, k}=0, \\
& \quad k=\mathrm{MeOH}, \mathrm{DME}
\end{aligned}
$$


In the cases of hybrid and core@shell pellet configurations, only one type of $i$-species mass balance (6) is present instead

$$
\frac{1}{x^{2}} \frac{\partial}{\partial x}\left(x^{2} D_{\mathrm{eff}, i} \rho_{g} \frac{\partial \omega_{\mathrm{s}, i}}{\partial x}\right)+\mathrm{MW}_{i} \sum_{k} \rho_{\mathrm{s}, k} \xi_{k}(x) \sum_{j=1}^{\mathrm{NR}} \nu_{i j} R_{j, k}=0
$$

The volumetric fractions $\xi_{k}(x)$ account for the distribution of two different active phases $(\mathrm{MeOH}$ synthesis and methanol dehydration to DME). In the case of the hybrid pellet, a perfect mixing of the two catalytic functions is assumed and the factors $\xi_{k}(x)$ are constant and equal to the overall volumetric faction $\xi_{k}^{\text {ov }}(7)$

$$
\xi_{k}(x)=\xi_{k}^{\mathrm{ov}}
$$

On the contrary, in the core@shell catalyst pellets, two welldefined zones (the core and the shell) are present, consisting of the two active phases that activate methanol synthesis and methanol dehydration, respectively. These layers are virtually separated by an internal interface at $x=r_{\text {int }}$. The internal radius $r_{\text {int }}$ of the interface is calculated considering the overall catalyst volumetric fraction as reported in eqs 8 and 9.

$$
\begin{aligned}
& r_{\text {int }}^{3} / r_{\mathrm{p}}^{3}=\xi_{\mathrm{MeOH}}^{\mathrm{ov}}, \quad \text { for MeOH@DME } \\
& r_{\text {int }}^{3} / r_{\mathrm{p}}^{3}=\xi_{\mathrm{DME}}^{\mathrm{ov}}, \quad \text { for DME@MeOH }
\end{aligned}
$$

Factors $\xi_{k}(x)$ assume the value of 1 or 0 in the core or shell, respectively, in correspondence to the active phase to which they refer (10)

for MeOH@DME

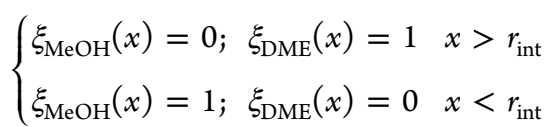

for DME@MeOH

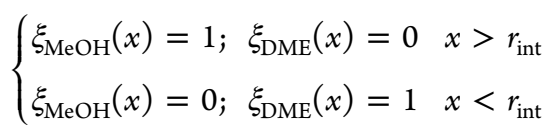

The boundary conditions on the catalyst surface $\left(x=r_{\mathrm{p}}\right)$ and in the pellet center $(x=0)$ are the same for all of the configurations analyzed (11)

$$
\begin{cases}\omega_{\mathrm{s}, i}=\omega_{\text {surf }, i} & x=r_{\mathrm{p}} \\ \frac{\partial \omega_{\mathrm{s}, i}}{\partial x}=0 & x=0\end{cases}
$$

For $\mathrm{MeOH} @ \mathrm{DME}$ and $\mathrm{DME} @ \mathrm{MeOH}$ pellets, the continuity of fluxes between the two catalyst phases is also imposed at the interface (12)

$$
\begin{aligned}
& \left.D_{\mathrm{eff}, i} \frac{\partial \omega_{\mathrm{s}, i}}{\partial x}\right|_{r_{\text {int }}}=\left.D_{\mathrm{eff}, i} \frac{\partial \omega_{\mathrm{s}, i}}{\partial x}\right|_{r_{\text {int- }}} \quad x=r_{\text {int }} \\
& \left.\omega_{\mathrm{s}, i}\right|_{r_{\text {int }+}}=\left.\omega_{\mathrm{s}, i}\right|_{r_{\text {int }}}
\end{aligned}
$$

2.3. Average Reaction Rate and Catalyst Effectiveness Factor. The adopted kinetic model accounts for the methanol synthesis from $\mathrm{CO}_{2}$ (2), WGS (3), and methanol dehydration to DME (4). The average reaction rate inside the catalyst pellet is calculated as reported in eq 13. In the case of the hybrid pellet or the mechanical mixture configuration, the integration domain corresponds to the whole pellet (between $x$ $=0$ and $r_{\mathrm{p}}$ ), while in the case of the core@shell configuration, the average rate is calculated in the interval between $x=0$ and $r_{\text {int }}$ for the core and between $x=r_{\text {int }}$ and $r_{\mathrm{p}}$ for the shell.

$$
\begin{aligned}
& R_{j, k}^{\mathrm{av}}=\frac{3 \int_{0}^{r_{\mathrm{p}}} R_{j, k} x^{2} \mathrm{~d} x}{r_{\mathrm{p}}^{3}} \\
& R_{j, k}^{\mathrm{av}, \text { shell }}=\frac{3 \int_{r_{\text {int }}}^{r_{\mathrm{p}}} R_{j, k} x^{2} \mathrm{~d} x}{r_{\mathrm{p}}^{3}-r_{\text {int }}^{3}} \\
& R_{j, k}^{\text {av, core }}=\frac{3 \int_{0}^{r_{\text {int }}} R_{j, k} x^{2} \mathrm{~d} x}{r_{\text {int }}^{3}}
\end{aligned}
$$

The $k$-catalyst effectiveness factor with respect to the $j$ reaction is calculated as the ratio of the average reaction rate inside the catalyst pellet to the reaction rate on the catalyst external surface (14)

$$
\eta_{j, k}=\frac{R_{j, k}^{\mathrm{av}}}{R_{j, k}^{\text {surf }}}
$$

The effective reaction rates used in the $2 \mathrm{D}$ mass balances at the reactor level are then calculated as the product of the average reaction rate times the overall volumetric catalyst fraction $\xi_{k}^{\text {ov }}(15)$

$$
R_{j, k}^{\mathrm{eff}}=\xi_{k}^{\mathrm{ov}} R_{j, k}^{\mathrm{av}}
$$

2.4. 2D Reactor $i$-Species Mass Balance. The gas-phase mass balances, written in cylindrical coordinates, include convection, radial mass diffusion, and mass transfer between gas and solid phases terms. Axial diffusion effects are neglected.

In the case of the mechanical mixture of pellets, the gassolid mass transfer term (16) accounts for the presence of the two separated catalyst phases ( $\mathrm{MeOH}$ and DME). Accordingly, the specific surface areas of the $k$-catalyst $a_{\mathrm{v}, k}$ are multiplied for the respective overall volumetric catalyst fraction $\xi_{k}^{\text {ov }}$ as reported in eq 17

$$
\begin{gathered}
-W_{\mathrm{t}} \frac{\partial \omega_{\mathrm{g}, i}}{\partial z}+\rho_{\mathrm{g}} D_{\mathrm{er}, i}\left(\frac{\partial^{2} \omega_{\mathrm{g}, i}}{\partial r^{2}}+\frac{1}{r} \frac{\partial \omega_{\mathrm{g}, i}}{\partial r}\right) \\
+\sum_{k} \rho_{\mathrm{g}} K_{\mathrm{m}, i} a_{\mathrm{v}, k}\left(\omega_{\mathrm{sur}, k, i}-\omega_{\mathrm{g}, i}\right)
\end{gathered}
$$$$
=0
$$

$$
a_{\mathrm{v}, k}=\xi_{k}^{\mathrm{ov}} \frac{S_{\mathrm{p}}}{V_{\mathrm{p}}}(1-\varepsilon), \quad k=\mathrm{MeOH}, \mathrm{DME}
$$

Two independent interphase continuity equations (18), one for each $k$-solid phase, are required to balance the gas-solid mass transfer and the rate of production/consumption of the $i$ species.

$$
\rho_{\mathrm{g}} K_{\mathrm{m}, i} a_{\mathrm{v}, k}\left(\omega_{\mathrm{g}, i}-\omega_{\text {surf } k, i}\right)+\mathrm{MW}_{i}(1-\varepsilon) \rho_{\mathrm{s}, k} \sum_{j=1}^{\mathrm{NR}} \nu_{i j} R_{j, k}^{\mathrm{eff}}=0
$$

In the cases of hybrid and core@shell pellet configurations, only one gas-solid mass transfer term is needed (19) with the specific surface area computed with eq 20 


$$
\begin{aligned}
& -W_{\mathrm{t}} \frac{\partial \omega_{\mathrm{g}, i}}{\partial z}+\rho_{\mathrm{g}} D_{\mathrm{er}, i}\left(\frac{\partial^{2} \omega_{\mathrm{g}, i}}{\partial r^{2}}+\frac{1}{r} \frac{\partial \omega_{\mathrm{g}, i}}{\partial r}\right) \\
& \quad+\rho_{\mathrm{g}} K_{\mathrm{m}, i} a_{\mathrm{v}}\left(\omega_{\mathrm{surf}, i}-\omega_{\mathrm{g}, i}\right) \\
& =0 \\
& a_{\mathrm{v}}=\frac{S_{\mathrm{p}}}{V_{\mathrm{p}}}(1-\varepsilon)
\end{aligned}
$$

The single interphase continuity equation (21) accounts for the presence of the two different $k$-catalyst phases inside the pellet.

$$
\begin{aligned}
& \rho_{\mathrm{g}} K_{\mathrm{m}, i} a_{\mathrm{v}}\left(\omega_{\mathrm{g}, i}-\omega_{\mathrm{surf}, i}\right)+(1-\varepsilon) \mathrm{MW}_{i} \sum_{k} \rho_{\mathrm{s}, k} \sum_{j=1}^{\mathrm{NR}} \nu_{i j} R_{j, k}^{\mathrm{eff}} \\
& \quad=0
\end{aligned}
$$

The boundary conditions for the mass balances (22) are the same for all catalyst configurations

$$
\begin{cases}\omega_{\mathrm{g}, i}=\omega_{\mathrm{g}, i}^{0} & z=0 \\ \frac{\partial \omega_{\mathrm{g}, i}}{\partial r}=0 & r=0 \\ \frac{\partial \omega_{\mathrm{g}, i}}{\partial r}=0 & r=d_{\mathrm{t}} / 2\end{cases}
$$

2.5. 2D Reactor Energy Balance. The energy balance for the gas phase accounts for the axial convection, the effective radial heat conduction, and the heat transfer between the gas and solid phases. Axial conduction terms are neglected $\left(L_{\mathrm{t}} / d_{\mathrm{p}}\right.$ $>1000)$. The consideration previously made for the mass balances regarding the differences between the hybrid/core@ shell and mechanical mixture catalyst configurations also applies to the energy balances.

The energy balance and the interphase continuity equations for the mechanical mixture configuration are given by eqs 23 and 24, respectively. In this case, two different solid temperatures $T_{s, k}$ one for each $k$-catalyst phase, are considered with the corresponding gas-solid heat transfer and heat generation terms.

$$
\begin{aligned}
& -W_{\mathrm{t}} C_{\mathrm{p}, \mathrm{g}} \frac{\partial T_{\mathrm{g}}}{\partial z}+\lambda_{\mathrm{eff}, r}\left(\frac{\partial^{2} T_{\mathrm{g}}}{\partial r^{2}}+\frac{1}{r} \frac{\partial T_{\mathrm{g}}}{\partial r}\right) \\
& +\sum_{k} h_{\mathrm{gs}} a_{\mathrm{v}, k}\left(T_{\mathrm{s}, k}-T_{\mathrm{g}}\right) \\
& =0
\end{aligned}
$$

$$
h_{\mathrm{gs}} a_{\mathrm{v}, k}\left(T_{\mathrm{g}}-T_{\mathrm{s}, k}\right)+(1-\varepsilon) \rho_{\mathrm{s}, k} \sum_{j=1}^{\mathrm{NR}} R_{j, k}^{\mathrm{eff}}\left(-\Delta H_{\mathrm{r}, j}\right)=0
$$

Equation 25 describes the gas-phase energy balance equation for the hybrid pellet and core@shell configurations.

$$
-W_{\mathrm{t}} C_{\mathrm{p}, \mathrm{g}} \frac{\partial T_{\mathrm{g}}}{\partial z}+\lambda_{\mathrm{eff}, \mathrm{r}}\left(\frac{\partial^{2} T_{\mathrm{g}}}{\partial r^{2}}+\frac{1}{r} \frac{\partial T_{\mathrm{g}}}{\partial r}\right)+h_{\mathrm{gs}} a_{\mathrm{v}}\left(T_{\mathrm{s}}-T_{\mathrm{g}}\right)=0
$$

The interphase continuity equation (26) accounts for the balance between the enthalpy gas-solid exchange and the enthalpy generation

$$
h_{\mathrm{gs}} a_{\mathrm{v}}\left(T_{\mathrm{g}}-T_{\mathrm{s}}\right)+(1-\varepsilon) \sum_{k} \rho_{\mathrm{s}, k} \sum_{j=1}^{\mathrm{NR}} \nu_{i j} R_{j, k}^{\mathrm{eff}}\left(-\Delta H_{\mathrm{r}, j}\right)=0
$$

The boundary conditions (27) are the same for every configuration

$$
\begin{cases}T_{\mathrm{g}}=T_{\mathrm{g}}^{0} & z=0 \\ \frac{\partial T_{\mathrm{g}}}{\partial r}=0 & r=0 \\ \lambda_{\text {eff, } \mathrm{r}} \frac{\partial T_{\mathrm{g}}}{\partial r}=h_{\mathrm{w}}\left(T_{\text {cool }}-T_{\mathrm{g}}\right) & r=d_{\mathrm{t}} / 2\end{cases}
$$

The wall temperature is assumed equal to the boiling water temperature $T_{\text {cool }}$ used as the coolant.

2.6. Momentum Balance. The momentum balance (28) is used to calculate the pressure drops along the reactor

$$
\frac{\rho_{\mathrm{g}}}{W_{\mathrm{t}}^{2}} \frac{\partial P}{\partial z}+f_{\mathrm{m}} a_{\mathrm{v}}=0
$$

A boundary condition at the reactor inlet is given (29)

$$
P=P^{0} \quad z=0
$$

Low-pressure drops $(\Delta P<1$ bar $)$ have been calculated in all of the simulations.

2.7. Kinetic Scheme. The kinetic scheme developed by $\mathrm{Ng}$ et al. $^{62}$ for the direct DME synthesis is adopted for the evaluation of the reaction rates. This scheme was obtained by coupling the kinetics for methanol synthesis and methanol dehydration to DME previously developed by Vanden Bussche et al. $^{63}$ and Berčic et al., ${ }^{64,65}$ respectively. The kinetic parameters were obtained in ref 62 by refitting the parameters against the experimental data obtained under direct DME synthesis conditions (50 bar, $250{ }^{\circ} \mathrm{C}, \mathrm{H}_{2} / \mathrm{CO}_{x}=1-4, \mathrm{CO} /$ $\left.\mathrm{CO}_{x}=0-1\right)$ using a CZA methanol synthesis catalyst and $\mathrm{Al}_{2} \mathrm{O}_{3}$ as a dehydration catalyst. Rate expressions 30, 31, and 32 refer to methanol synthesis from $\mathrm{CO}_{2}$, reverse water-gas shift, and methanol dehydration, respectively

$$
\begin{aligned}
& R_{1}=\frac{k_{1} f_{\mathrm{CO}_{2}} f_{\mathrm{H}_{2}}\left(1-\left(1 / K_{\mathrm{eq}, 1}\right)\left(f_{\mathrm{H}_{2} \mathrm{O}} f_{\mathrm{CH}_{3} \mathrm{OH}} / f_{\mathrm{CO}_{2}} f_{\mathrm{H}_{2}}^{3}\right)\right)}{\left(1+K_{\mathrm{H}_{2} \mathrm{O} / \mathrm{H}_{2}} f_{\mathrm{H}_{2} \mathrm{O}} / f_{\mathrm{H}_{2}}+\sqrt{K_{\mathrm{H}_{2}} f_{\mathrm{H}_{2}}}+K_{\mathrm{H}_{2} \mathrm{O}}^{\prime} f_{\mathrm{H}_{2} \mathrm{O}}\right)^{3}} \\
& R_{2}=\frac{k_{2} f_{\mathrm{CO}_{2}}\left(1-\left(1 / K_{\mathrm{eq}, 2}\right)\left(f_{\mathrm{CO}} f_{\mathrm{H}_{2} \mathrm{O}} / f_{\mathrm{CO}_{2}} f_{\mathrm{H}_{2}}\right)\right)}{\left(1+K_{\mathrm{H}_{2} \mathrm{O} / \mathrm{H}_{2}} f_{\mathrm{H}_{2} \mathrm{O}} / f_{\mathrm{H}_{2}}+\sqrt{K_{\mathrm{H}_{2}} f_{\mathrm{H}_{2}}}+K_{\mathrm{H}_{2} \mathrm{O}}^{\prime} f_{\mathrm{H}_{2} \mathrm{O}}\right)} \\
& R_{3}=\frac{k_{3} K_{\mathrm{CH}_{3} \mathrm{OH}}^{2} C_{\mathrm{CH}_{3} \mathrm{OH}}^{2}\left(1-\left(C_{\mathrm{H}_{2} \mathrm{O}} C_{\mathrm{DME}} / C_{\mathrm{CH}_{3} \mathrm{OH}}^{2} K_{\mathrm{eq}, 3}\right)\right)}{\left(1+2 \sqrt{K_{\mathrm{CH}_{3} \mathrm{OH}} C_{\mathrm{CH}_{3} \mathrm{OH}}}+K^{\prime \prime}{ }_{\mathrm{H}_{2} \mathrm{O}} C_{\mathrm{H}_{2} \mathrm{O}}\right)^{4}}
\end{aligned}
$$

All of the parameters in eqs 30, 31, and 32 are calculated according to the equation reported in Table S1 (Supporting information S1) taken from the literature references. ${ }^{52,62,66}$ Reaction rates $R_{1}$ and $R_{2}$ refer to the $\mathrm{MeOH}$ synthesis function, while rate $R_{3}$ refers to the DME synthesis function. Fugacities 
to be used in kinetic equations are calculated using the gPROMS Multiflash 4.3 utility tools, which implement the Redlick-Kwong-Soave (RKS) equation of state.

2.8. Physicochemical Properties and Transport Correlations. The physical and chemical properties of the reacting mixture (average molecular weight, specific heat, density, viscosity, and thermal conductivity) are calculated using the gPROMS Multiflash 4.3 utility tool. The viscosity and conductivity are calculated using the "Super TRAPP" model ${ }^{67}$ Diffusivities and transport coefficients are calculated according to literature correlations. ${ }^{68-75}$ Specifically, calculation methods of binary and gas mixture molecular diffusivities are reported in Supporting Information S2.1, effective intraporous diffusivities are reported in Supporting Information S2.2, gas-solid mass and heat transport correlations are reported in Supporting Information S2.3, effective radial transport properties in catalyst bed are reported in Supporting Information S2.4, and the friction factor used in pressure drop calculations is reported in Supporting Information S2.5.

2.9. Numerical Solution Scheme. The numerical solution of the resulting differential-algebraic system of equations is obtained using the gPROMS software numerical solver framework. A first-order backward finite-difference method (BFDM) is used to discretize the axial coordinate, while a third-order orthogonal collocation on finite elements method (OCFEM) is used for the radial and the pellet coordinates. A total of 50 discretization points are used along the axial coordinate in a nonuniform grid: the points are spaced using a logarithm transformation implemented in gPROMS with a transformation parameter $\alpha=15$. Two uniform finite elements for the radial coordinate are used. Eight uniform finite elements for the hybrid and mechanical mixture configurations are used for the internal pellet coordinate, while in the case of the core@shell configuration, four uniform finite elements for the shell and four for the core are employed. The numbers of axial discretization points and of radial and internal pellet finite elements were checked by a convergence analysis. The discretization grid is visualized in Supporting Information S3.

The resulting nonlinear algebraic equation system (130950 equations in the mechanical mixture case, 66900 equations in hybrid and core@shell cases) is solved using the "BDNLSOL" (Block Decomposition NonLinear SOLver) block decomposition and triangularization method, implemented in gPROMS, while the single blocks are solved with the "SPARSE" solver based on a Newtonian-type method. The relative convergence tolerance is set at $1 \times 10^{-5}$ in the final solution.

\section{RESULTS AND DISCUSSION}

3.1. Hybrid vs Mechanical Mixture. The hybrid pellet and the mechanical mixture configurations, which are schematically represented in Figure 1, are compared in this section.

Reactor design parameters and operating conditions adopted in the simulations are reported in Tables 1 and 2. A 1 in nominal diameter (internal diameter, $d_{\mathrm{t}}=25.65 \mathrm{~mm}$ ) and $6 \mathrm{~m}$ long tubes are taken as typical geometry from full-scale results given in the literature. ${ }^{22,47}$ A $4.86 \mathrm{~mm}$ diameter of the spherical catalyst particles is set, equal to the equivalent diameter of typical commercial methanol catalyst particles. ${ }^{76}$ A feed composition with a $\mathrm{H}_{2} / \mathrm{CO}$ molar ratio equal to $2: 1$, a $\mathrm{CO} /$ $\mathrm{CO}_{2}$ ratio of $2: 1$, and an inert content $\left(\mathrm{CH}_{4}\right)$ of about $8 \%$ is

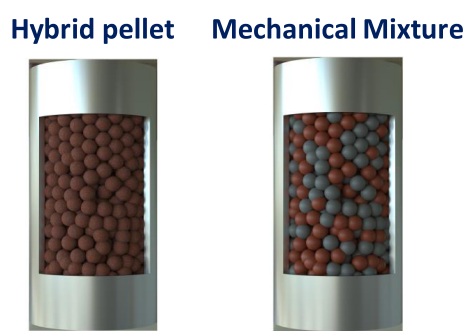

Figure 1. Hybrid (left) and mechanical mixture (right) configuration sketches.

\section{Table 1. Input Variables Used in the Simulations}

\begin{tabular}{lll} 
variable & \multicolumn{1}{c}{ value } & unit \\
$T_{\mathrm{g}}^{0}$ & 500 & $\mathrm{~K}$ \\
$T_{\text {cool }}$ & 511 & $\mathrm{~K}$ \\
$P^{0}$ & 50 & $\mathrm{bar}$ \\
$\mathrm{GHSV}$ & 1500 & $\mathrm{~h}^{-1}$ \\
$L_{\mathrm{t}}$ & 6 & $\mathrm{~m}$ \\
$d_{\mathrm{t}}$ & $2.565 \times 10^{-2}$ & $\mathrm{~m}$ \\
$d_{\mathrm{p}}$ & $4.86 \times 10^{-3}$ & $\mathrm{~m}$ \\
$\rho_{\mathrm{s}, \mathrm{MeOH}}$ & 1712 & $\mathrm{~kg} / \mathrm{m}^{3}$ \\
$\rho_{\mathrm{s}, \mathrm{DME}}$ & 1285 & $\mathrm{~kg} / \mathrm{m}^{3}$ \\
$\xi_{\mathrm{MeOH}}$ & 0.6 & \\
$\xi_{\mathrm{DME}}$ & 0.4 & \\
$\varepsilon_{\mathrm{p}} / \tau_{\mathrm{MeOH}}$ & 0.123 & \\
$\varepsilon_{\mathrm{p}} / \tau_{\mathrm{DME}}$ & 0.153 & \\
$r_{\text {pore,MeOH }}$ & 9.7 & $\mathrm{~nm}$ \\
$r_{\text {pore, } \mathrm{DME}}$ & 11 & $\mathrm{~nm}$
\end{tabular}

Table 2. Inlet Gas Composition

\begin{tabular}{cccc} 
compound & case A & case B & unit \\
$\mathrm{CO}$ & 26.30 & 13.41 & $\%$ \\
$\mathrm{CO}_{2}$ & 13.15 & 13.41 & $\%$ \\
$\mathrm{H}_{2}$ & 52.60 & 65.23 & $\%$ \\
$\mathrm{CH}_{4}$ & 7.95 & 7.95 & $\%$ \\
\hline
\end{tabular}

considered as the inlet composition of direct synthesis DME reactors operating within a recycle loop (see case A in Table 2 ). A weight ratio of $\mathrm{MeOH} / \mathrm{DME}$ catalysts of 2 is assumed according to ref 62 , which results in a volumetric ratio of 1.5 considering the different catalyst bulk densities of CZA methanol synthesis and $\mathrm{Al}_{2} \mathrm{O}_{3}$ dehydration catalysts. ${ }^{64,76}$ The parameters $\left(\varepsilon_{\mathrm{p}} / \tau\right.$ and pore radius), used for the calculation of effective diffusivities in methanol synthesis and dehydration catalyst, respectively, are also reported in Table 1 . In the case of the hybrid pellets, the parameters are obtained as the volume average of the values of the two catalysts. In the core@ shell pellets, the parameters change in the two different layers according to the specific catalyst type.

The axial profiles of the cross-sectional average specific molar flow rates of reactants $\left(\mathrm{CO}, \mathrm{H}_{2}, \mathrm{CO}_{2}\right)$ and products $\left(\mathrm{H}_{2} \mathrm{O}, \mathrm{MeOH}, \mathrm{DME}\right)$ are plotted in Figure $2 \mathrm{a}, \mathrm{b}$, respectively. The consumption of $\mathrm{CO}$ and $\mathrm{H}_{2}$ is faster in the case of the hybrid pellet, while a net production of $\mathrm{CO}_{2}$ occurs in both cases (except in the very first part of the reactor loaded with the mechanical mixture), evidencing that $\mathrm{CO}_{2}$ production by WGS slightly prevails with respect to $\mathrm{CO}_{2}$ consumption by the methanol synthesis reaction. ${ }^{20-22,47}$ As a matter of fact, the WGS rate is limited by water production, which is higher in the hybrid configuration, resulting in a faster $\mathrm{CO}_{2}$ increase. Axial profiles of the methanol flow rate show a trend with a 

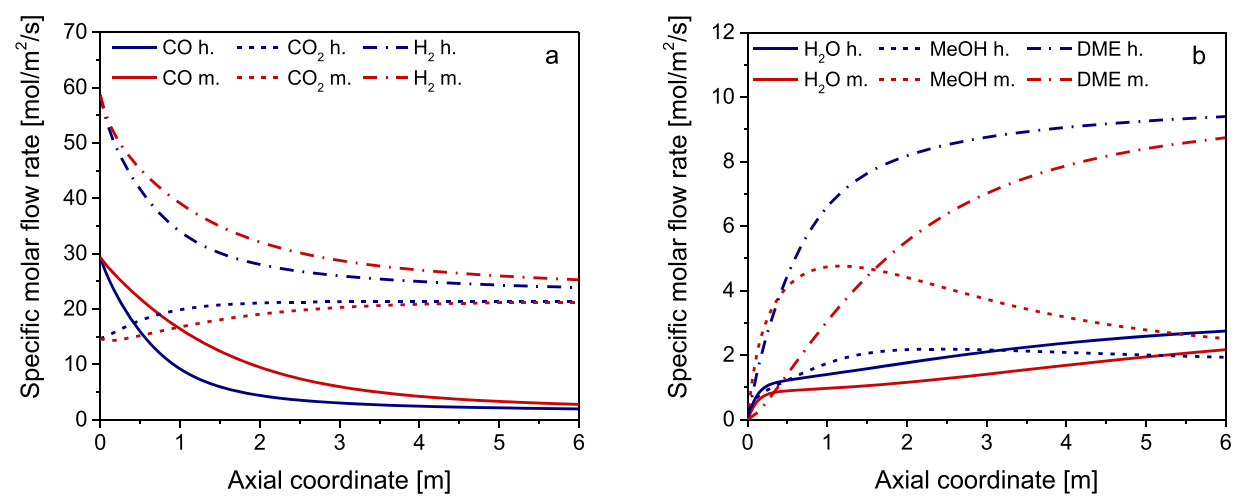

Figure 2. Axial profiles of the average specific molar flow rate of (a) reactants and (b) products with hybrid pellet (h) and mechanical mixture (m) configurations.

maximum, which is consistent with the intermediate nature of methanol in the process. ${ }^{44}$ All along the axial coordinate, the production of methanol is larger when using the mechanical mixture (Figure 2b). This is not a consequence of a faster methanol synthesis rate but depends on the less efficient methanol consumption by dehydration, as shown by the molar flow rate of DME, which increases much faster in the case of the hybrid pellet configuration.

The axial profiles of the DME carbon yield, calculated with eq 33, are shown in Figure 3 together with the target equilibrium value at the coolant temperature and inlet pressure.

$$
Y_{\mathrm{DME}}=\frac{2 F_{\mathrm{DME}}}{\left(F_{\mathrm{CO}}+F_{\mathrm{CO}_{2}}\right)_{\mathrm{in}}}
$$

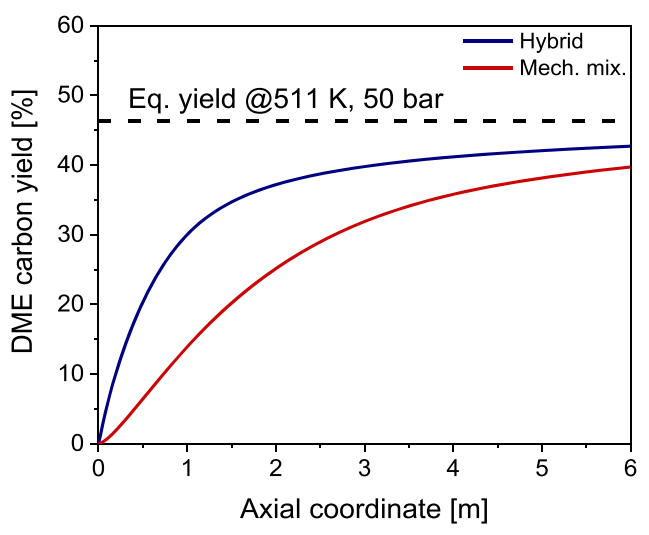

Figure 3. DME carbon yield profiles with hybrid pellet and mechanical mixture configurations.

In the case of the hybrid pellet configuration, the DME yield quickly increases in the first part of the reactor (30\% DME yield is reached at $1 \mathrm{~m}$ length) and then it levels off due to the approach to the thermodynamic equilibrium. Instead, in the case of the mechanical mixture, the yield increase is much slower (30\% DME yield at $2.7 \mathrm{~m}$ length). Although the equilibrium yield is not reached in both the cases, the hybrid pellet configuration markedly overcomes the performance of the mechanical mixture, in line with the literature reports. ${ }^{21}$

The temperature profiles are consistent with the previous observations. The 2D temperature map for the hybrid catalyst configuration is plotted in Figure $4 a$, showing the typical hotspot trend of exothermic processes in externally cooled
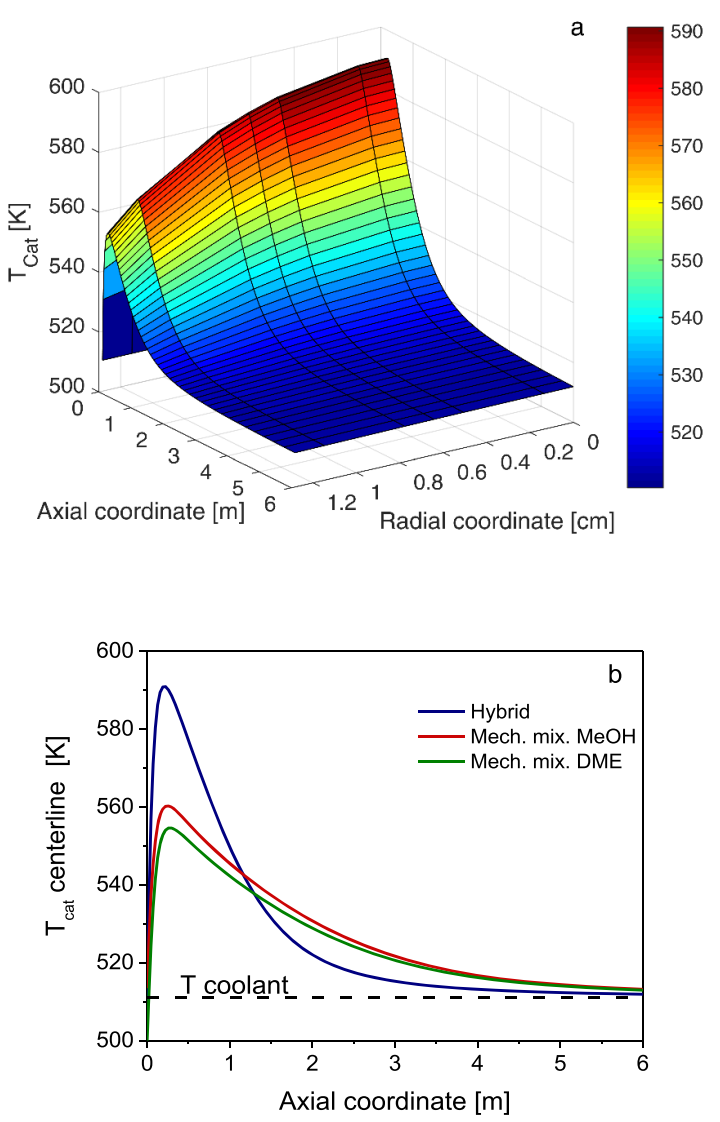

Figure 4. (a) Catalyst $2 \mathrm{D}$ temperature profile in the hybrid pellet configuration and (b) catalyst (hybrid, $\mathrm{MeOH}$, and DME catalysts in the mechanical mixture) temperature profile on the tube centerline.

catalytic reactors. The maximum temperature occurs along the centerline profile, which in Figure $4 \mathrm{~b}$ is plotted for the two different configurations.

In both cases, the temperature rapidly increases along the axial coordinate, reaching the hotspot in the very first part of the reactor and then gradually decreasing down to the coolant temperature. The higher reactant conversion rate obtained with the hybrid pellet configuration results in a faster heat release, which in turn causes a more pronounced hotspot temperature. As a matter of fact, the hotspot temperature in the case of the hybrid pellet is $590 \mathrm{~K}$, while in the case of the mechanical mixture is $560 \mathrm{~K}$ on the $\mathrm{MeOH}$ catalyst and $555 \mathrm{~K}$ on DME pellets. Such a difference is in line with previous 

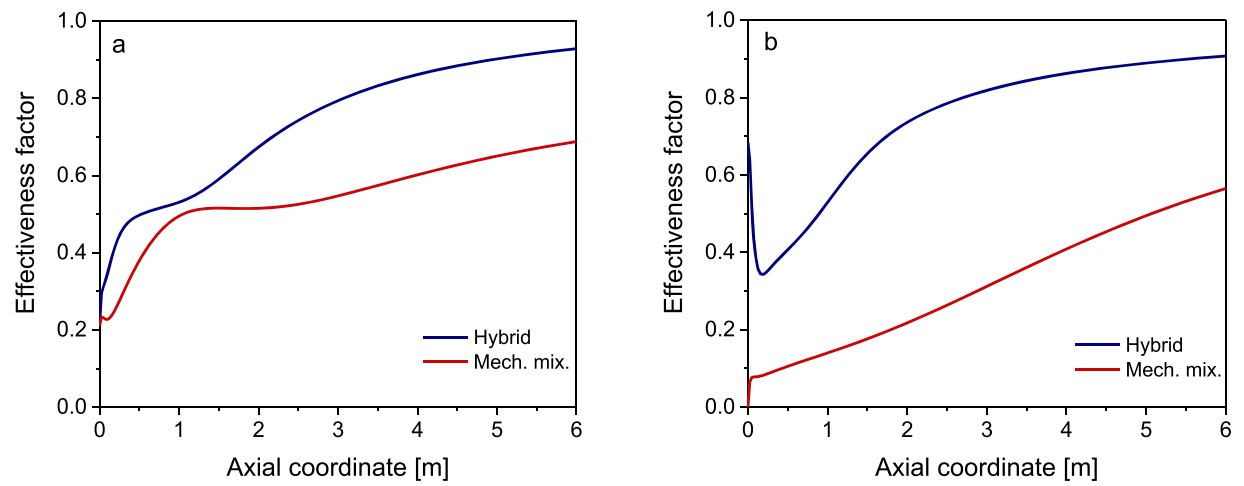

Figure 5. Catalyst pellet effectiveness factor centerline profiles for (a) methanol synthesis (b) methanol dehydration with hybrid pellet and mechanical mixture configurations.
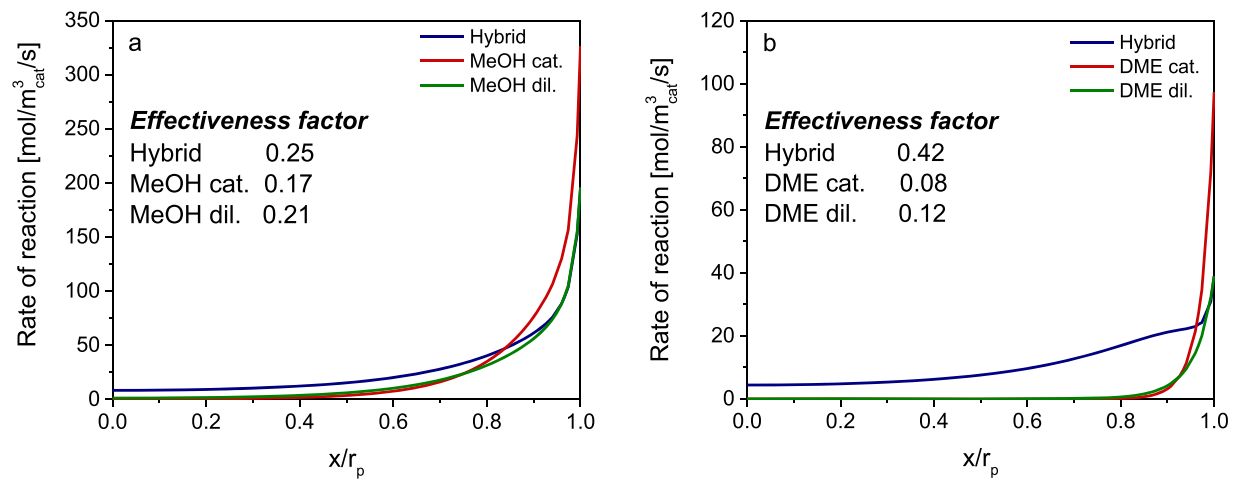

Figure 6. Reaction rate profiles inside catalyst pellets: (a) methanol synthesis and (b) methanol dehydration. Surface conditions: 50 bar, $543 \mathrm{~K}$; surface composition: $\mathrm{CO} 20 \%, \mathrm{CO}_{2} 17.5 \%, \mathrm{H}_{2} 52.3 \%, \mathrm{H}_{2} \mathrm{O} 0.5 \%, \mathrm{MeOH} 0.8 \%, \mathrm{DME} 0.6 \%, \mathrm{CH}_{4} 8.3 \%$.

literature results obtained with $1 \mathrm{D}$ mathematical modeling. ${ }^{21}$ Accordingly, the mechanical mixture guarantees a better hotspot control, which stands well below the temperature limit value of $573 \mathrm{~K}$, reported in the literature for stable catalyst operation ${ }^{77,78}$ avoiding the deactivation due to $\mathrm{Cu}$ cluster sintering.

The apparent higher catalyst activity shown by the hybrid pellet configuration is a consequence of the impact of intraporous mass transfer limitations, as evidenced by the differences in the effectiveness factors in the two layouts (Figure 5). The hybrid catalyst has a higher efficiency both in methanol synthesis and methanol dehydration, the gap with the mechanical mixture being more pronounced for this latter reaction. The efficiency of methanol synthesis monotonically grows along the axial coordinate and, in the case of the hybrid pellet configuration, gets close to unity in proximity to the reactor outlet, where the equilibrium approach makes the reaction quite slow. In the case of the mechanical mixture, the efficiency of methanol dehydration keeps very low along the whole reactor, linearly increasing from 0.07 to 0.55 along the axial coordinate. A similar trend was also reported by Song et al. ${ }^{21}$ for $\mathrm{Al}_{2} \mathrm{O}_{3}$ dehydration catalysts operating under direct synthesis DME conditions, at which the herein adopted kinetic has been refitted by $\mathrm{Ng}$ et al. ${ }^{62}$ The reason for this behavior is likely related to the relatively low water concentration (below $4 \%$ ) with respect to that relevant to methanol dehydration in the indirect DME synthesis process, which enhances the DME production rate, making the diffusional limitations more severe. On the other hand, in the case of the hybrid pellet, the efficiency curve goes through a minimum value of 0.35 in correspondence to the hotspot temperature, rapidly increasing to values higher than 0.8 in the second half of the reactor.

To better understand these differences, intrapellet reaction rate profiles are calculated using the $1 \mathrm{D}$ isothermal pellet model for the cases of a hybrid catalyst, a $\mathrm{MeOH}$ catalyst, and a DME catalyst, assuming identical conditions on the external surface. The analysis also includes the cases of the "diluted" pellet configuration that can be viewed as hybrid pellets in which one of the catalysts is replaced by an inert solid phase. In this way, it is possible to evaluate whether the efficiency increase obtained with the hybrid pellet is mainly related to a mere effect of the reciprocal dilution of the two active phases.

A pressure of 50 bar is set in the calculations together with a temperature of $543 \mathrm{~K}$ and the following molar composition on the external pellet surface: $\mathrm{CO} 20 \%, \mathrm{CO}_{2} 17.5 \%, \mathrm{H}_{2} 52.3 \%$, $\mathrm{H}_{2} \mathrm{O} 0.5 \%, \mathrm{MeOH} 0.8 \%$, DME $0.6 \%$, and $\mathrm{CH}_{4}$ 8.3\%. This composition corresponds to that typically found in the first part of the reactor, where the reaction rates are higher, making the effects of diffusional phenomena stronger.

The reaction rate profiles and the corresponding values of the catalyst effectiveness factors obtained with the different pellet configurations (pure, hybrid, and diluted) are reported in Figure $6 a, b$. On the external pellet surface, in the case of the diluted and the hybrid pellet configurations, the volumetric rates of both methanol synthesis and methanol dehydration reactions are lower than those of the pure pellets by a factor equal to the dilution ratio. This has no impact on the reactor performances since in the mechanical mixture the same dilution factor of pellets applies to the bed scale (eq 17).

For all of the catalyst configurations, due to the progressive decrease of reactant concentrations, the rate of the methanol 

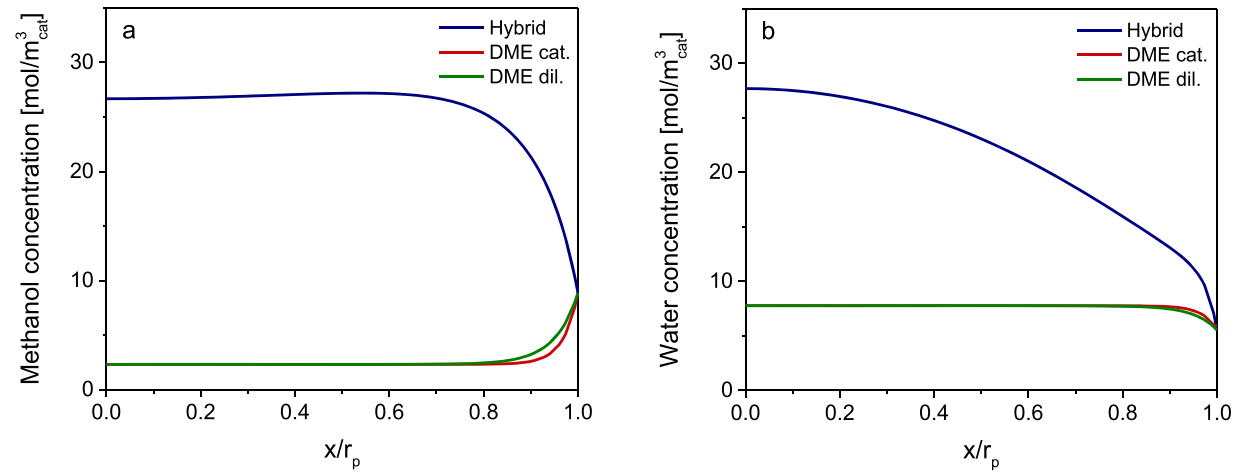

Figure 7. (a) Methanol and (b) water concentration profiles inside the catalyst pellet (hybrid, pure dehydration, and diluted dehydration catalysts). Surface conditions: 50 bar, $543 \mathrm{~K}$; surface composition: $\mathrm{CO} 20 \%, \mathrm{CO}_{2} 17.5 \%, \mathrm{H}_{2} 52.3 \%, \mathrm{H}_{2} \mathrm{O} 0.5 \%, \mathrm{MeOH} 0.8 \%, \mathrm{DME}_{0.6 \%} \mathrm{CH}_{4} 8.3 \%$.

synthesis (Figure 6a) decreases from the outer surface to the center of the pellet. Such a decreasing trend is stronger in the pure catalyst pellet, resulting in the lowest efficiency value, while it is more gradual in the case of both the hybrid and the diluted pellets. These latter two are similar, except in the deep core where the methanol synthesis rate goes to zero in the diluted pellet due to the close approach to thermodynamic equilibrium. Conversely, a significant rate is still present in the hybrid pellet due to the law of mass action associated with methanol consumption by the dehydration catalyst. As a result, the effectiveness increases from 0.17 for the pure catalyst to 0.21 for the diluted one, up to 0.25 for the hybrid pellet, indicating that dilution alone does not fully account for the advantage associated with the hybrid pellet configuration.

The situation is completely different when the methanol dehydration to DME is considered (Figure 6b). In this case, the pure and the diluted catalyst pellets show similar trends: the reaction rate rapidly decreases in the external part of the pellet, approaching zero due to the equilibrium approach in the core. This points out a very strong effect of the internal diffusion limitations.

It is worth noting that the effectiveness factor of the DME pellet catalyst is much lower than that of the $\mathrm{MeOH}$ catalyst, underlining that the dehydration reaction is significantly more limited by internal diffusion than the $\mathrm{MeOH}$ synthesis one. As expected, the diluted configuration shows a $50 \%$ increase of efficiency ( 0.12 vs 0.08 ), which is consistent with the 2.5 volumetric dilution factor adopted in the calculations. However, such a dilution effect does not explain the high efficiency calculated for the hybrid pellet (0.42). In this case, due to the consecutive nature of the reaction network within the pellet, the rate profile cannot be described according to the typical trend of a simple diffusion-limited reaction. Accordingly, the reaction rate gradually decreases along the pellet coordinate without dropping to zero (Figure $6 \mathrm{~b}$ ).

In fact, while in the diluted and pure DME catalysts, methanol is consumed in the external part of the pellet, reaching a constant concentration consistent with the thermodynamic equilibrium of the dehydration reaction, in the hybrid pellet, the local formation of methanol thermodynamically (and kinetically) sustains the DME production (Figure 7a), the gradual decrease of the dehydration rate being mainly related to the inhibiting effect of the increasing water concentration (Figure 7b).

As a whole, the superior yield performances of the hybrid configuration rely on the synergy between the reactions involved in the direct DME synthesis associated with the local interplay of the two catalysts, which enhances the effectiveness factors. On the other hand, the higher conversion rate makes the thermal management of the reactor more difficult. Besides, as mentioned in Section 1, the hybrid catalyst may suffer from deactivation due to the intimate contact between the two active phases. $^{26-32}$ The core@shell pellet configurations are investigated in the next section as a possible tradeoff between the different issues described above.

3.2. Core@Shell Configurations. The analysis is performed considering the same operating conditions reported in Table 1 and case A feed composition in Table 2. The core@ shell catalyst pellet configurations, i.e., MeOH@DME and $\mathrm{DME} @ \mathrm{MeOH}$, are analyzed and compared with the hybrid pellet and the mechanical mixture configurations used as benchmarks. The schematic representation of the core@shell catalyst pellets is reported in Figure 8. It is important to remark

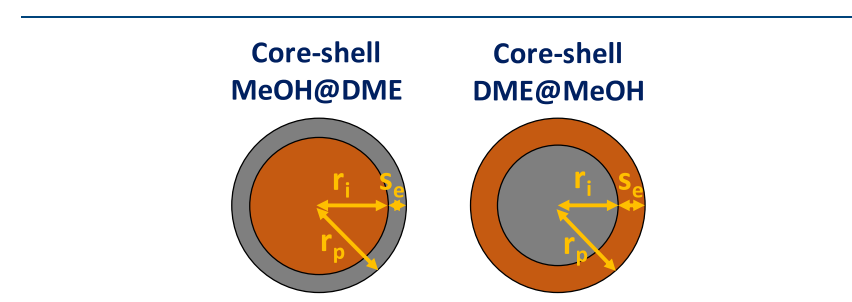

Figure 8. Sketches of core@shell pellets (brown, $\mathrm{MeOH}$ catalyst; gray, DME catalyst).

that, to have the same catalyst load for all of the considered reactor configurations, all of the pellets have the same weight and volume ratio between the $\mathrm{MeOH}$ and DME catalysts (respectively $2: 1 \mathrm{w} / \mathrm{w}$ and $1.5: 1 \mathrm{v} / \mathrm{v}$ ). Considering that the pellets also have the same radius $\left(r_{\mathrm{p}}=2.43 \mathrm{~mm}\right)$, the internal radius $r_{\text {int }}$ of the methanol catalyst core in the case of $\mathrm{MeOH} @$ DME is $2.04 \mathrm{~mm}$, while that of the external dehydration catalyst shell, $s_{\mathrm{e}}$, is $0.39 \mathrm{~mm}$ thick. However, due to the lower volume of the dehydration catalyst, the core in the DME@ $\mathrm{MeOH}$ case has a radius $r_{\text {int }}=1.80 \mathrm{~mm}$ and the methanol catalyst shell is $0.63 \mathrm{~mm}$ thick.

Figure 9a,b shows the axial profiles of the average specific molar flow rate of the $\mathrm{C}$-containing reactants $\left(\mathrm{CO}, \mathrm{CO}_{2}\right)$ and products (methanol and DME), respectively.

The ranking of the consumption rate of $\mathrm{CO}$ is as follows: hybrid > DME@MeOH > MeOH@DME > mechanical mixture. As previously discussed, the conversion of $\mathrm{CO}$ is the fastest in the hybrid pellet configuration, thanks to the synergy between the methanol synthesis and dehydration reactions. Figure $9 \mathrm{a}$ also confirms that $\mathrm{CO}_{2}$ is not a reactant 

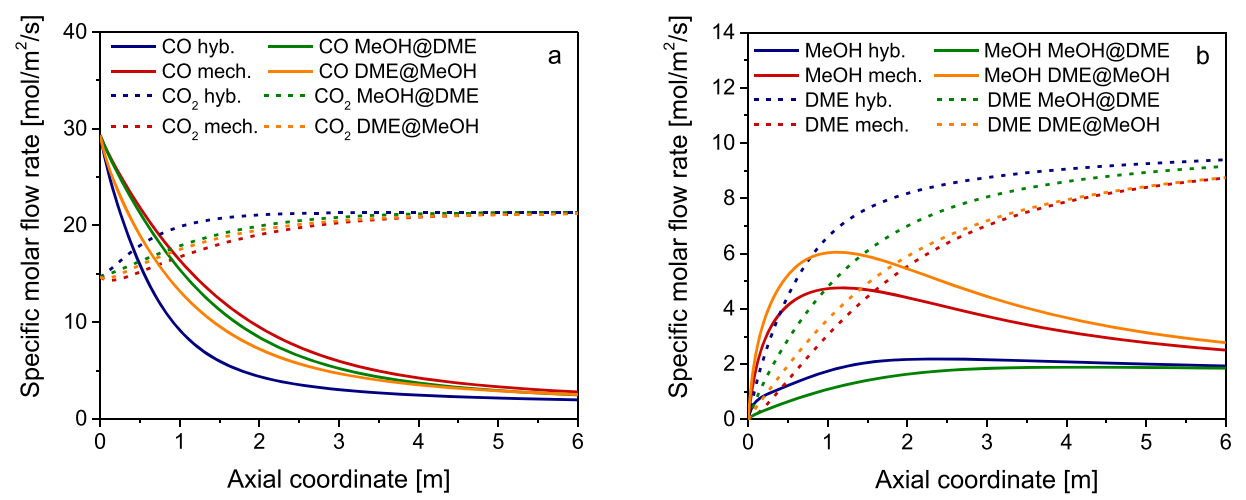

Figure 9. Axial profiles of the average specific molar flow rates of (a) reactants and (b) products with different catalyst configurations.

but rather a product of the process, as demonstrated by its flow rate that increases continuously along the axial coordinate.

Wide differences are observed in the distribution of the main products, i.e., methanol and DME. Figure $9 \mathrm{~b}$ shows that the $\mathrm{DME} @ \mathrm{MeOH}$ catalyst exhibits the highest methanol net production rate, with a low DME production close to that obtained with the mechanical mixture. On the other hand, the $\mathrm{MeOH} @ \mathrm{DME}$ catalyst, showing a DME formation rate similar to the hybrid pellet together with the lowest methanol net production rate, is highly selective to DME and widely outperforms the mechanical mixture. The higher selectivity to DME in the case of the MeOH@DME configuration has been also experimentally observed in refs $19,34,37$.

The performances of the reactor, evaluated on the basis of the DME yield and centerline catalyst temperature, are consistent with the previous observations. The hybrid pellet configuration provides the maximum DME yield (Figure 10), followed by the selective $\mathrm{MeOH} @ \mathrm{DME}$ core@shell configuration, which closely approaches the DME productivity of the hybrid pellet at the end of the reactor.

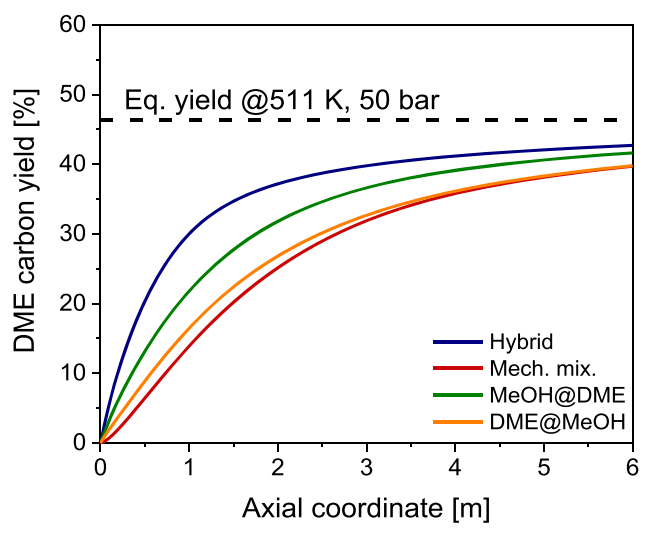

Figure 10. DME carbon yield profiles with different catalyst configurations.

Conversely, the DME@MeOH configuration, which is more selective to methanol, shows a DME yield close to that obtained with the mechanical mixture.

The temperature profiles in Figure 11 are consistent with the $\mathrm{CO}$ consumption trend in Figure 9a. In fact, the enthalpy release per mole of $\mathrm{CO}$ is similar for methanol and DME production $\left(\Delta H_{\mathrm{CH}_{3} \mathrm{OH}}^{0}=-90.5 \mathrm{~kJ} / \mathrm{mol}_{\mathrm{CO}}\right.$ vs $\Delta H_{\mathrm{DME}}^{0}=-104.0$ $\mathrm{kJ} / \mathrm{mol}_{\mathrm{CO}}$ ). Accordingly, the maximum $\mathrm{CO}$ consumption rate of the hybrid pellet configuration results in the most severe

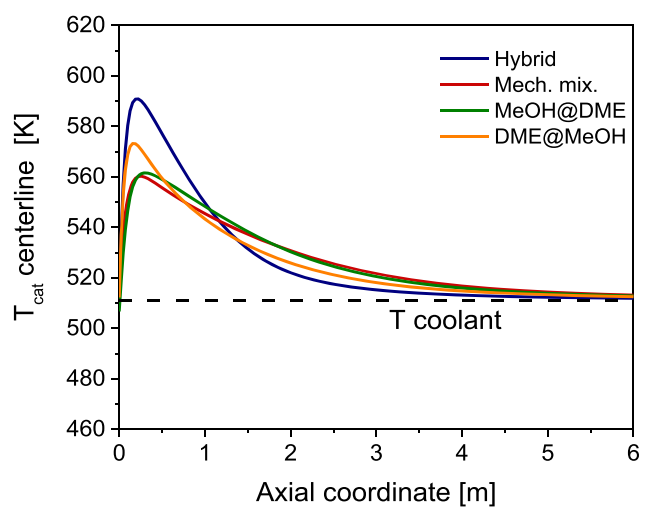

Figure 11. Catalyst temperature profile on the tube centerline with different catalyst configurations.

hotspot $\left(T_{\mathrm{hs}}=590 \mathrm{~K}\right)$, followed by the DME@MeOH pellet configuration $\left(T_{\mathrm{hs}}=573 \mathrm{~K}\right)$. The lower $\mathrm{CO}$ conversion rate of the MeOH@DME pellet configuration ensures a relatively mild hotspot $\left(T_{\mathrm{hs}}=561 \mathrm{~K}\right)$, practically equal to that of the methanol synthesis catalyst in the mechanical mixture. Nevertheless, thanks to the high selectivity, the MeOH@ DME pellet provides a DME yield comparable to that achieved with the hybrid pellet configuration.

As discussed in the previous section, the performance differences between the catalyst configurations are related to the effects of internal mass transfer limitations. In the coreshell catalyst pellets, the significance of the catalyst effectiveness factor is arguable since the surface where the reference reaction rate in eq 14 is taken can be located either on the external pellet surface or at the interface between the two catalytic layers.

A simple analysis of intraparticle diffusion effects can be performed by considering the effective diffusion lengths, volume-to-surface ratios $(V / S)$, for the different pellet configurations, reported in Table 3 . For the mechanical mixture, considering the spherical geometry of the pellets for both the methanol synthesis and DME synthesis catalysts, the

Table 3. Diffusion Lengths $[V / S(\mathrm{~mm})]$ of Methanol Synthesis and Methanol Dehydration Reactions in the Different Catalyst Configurations

$\begin{array}{lcccc} & \text { hybrid } & \text { mechanical } & \text { MeOH@DME } & \text { DME@MeOH } \\ \mathrm{MeOH} & 0.81 & 0.81 & 0.68 & 0.31 \\ \mathrm{DME} & & 0.81 & 0.19 & 0.60\end{array}$


diffusional length is equal to $d_{\mathrm{p}} / 6$. In the hybrid pellet, the same length can be assumed for the primary methanol synthesis reaction, whereas the definition is meaningless for the consecutive dehydration one. In the core@shell configurations, 1:6 of the internal core diameter can be taken for the corresponding reaction, whereas the ratio of the volume to the sum of the external surface and the interface surface must be considered in the shell, which roughly corresponds to half the shell thickness. The DME@MeOH catalyst shows the minimum diffusion length for the methanol synthesis, but the DME production in the core is still strongly diffusionlimited, resulting in high methanol production and low DME selectivity as previously evidenced. On the other hand, the $\mathrm{MeOH} @ \mathrm{DME}$ pellet minimizes the diffusion length of the methanol dehydration reaction, resulting in the high DME selectivity and yield as discussed above.

It is worth to remark that core@shell configurations markedly decrease the contact surface between the two catalyst formulations with respect to the hybrid pellets, which might reduce the deactivation rate. ${ }^{27}$ Besides, a very thin protective inert porous layer can be inserted between the two active layers to further mitigate cross-migration phenomena responsible for deactivation. $^{35}$

In the next sections, the comparative analysis of the different configurations is extended to other feed compositions and pressures to better understand the general value of the results reported above.

3.3. Sensitivity on Syngas Composition. To check the sensitivity of the previous results on the quality of the feed, a quite different syngas composition is considered (see case $\mathrm{B}$ in Table 2), characterized by a low $\mathrm{CO} / \mathrm{CO}_{2}$ ratio $\left(\mathrm{CO} / \mathrm{CO}_{2}=\right.$ $1)$, a stoichiometric module $\mathrm{M}=\left(\mathrm{H}_{2}-\mathrm{CO}_{2}\right) /\left(\mathrm{CO}+\mathrm{CO}_{2}\right)=2$, and the same inert molar fraction adopted in the reference case. This new composition refers to a typical syngas obtained from biomass gasification ${ }^{79}$ used to feed the direct DME synthesis process including a sorption enhanced unit that, differently from the conventional direct synthesis of DME, requires the same stoichiometric module of methanol synthesis. $^{80,81}$

The DME carbon yield profile along the reactor axis is shown in Figure 12 for the different catalyst configurations. Notably, the performance ranking is the same obtained with the composition used in the previous case $\left(\mathrm{CO} / \mathrm{CO}_{2}=2, M=\right.$ 1). Indeed, the hybrid configuration maximizes the DME yield,

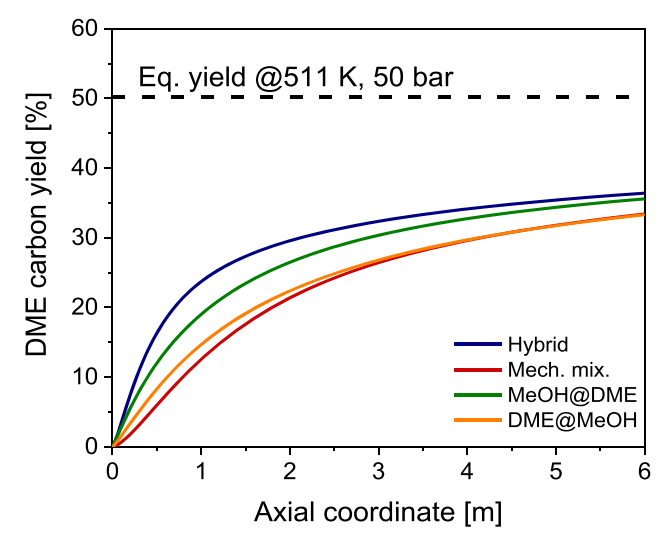

Figure 12. DME carbon yield profile along the reactor axial coordinate with different catalyst configurations using a feed with $M$ $=2$ and $\mathrm{CO} / \mathrm{CO}_{2}=1$. closely followed by $\mathrm{MeOH} @ \mathrm{DME}$, while DME@MeOH and mechanical mixture provide significantly lower yields.

The corresponding temperature profiles, reported in Figure 13, also follow the same trends as those reported in Figure 11

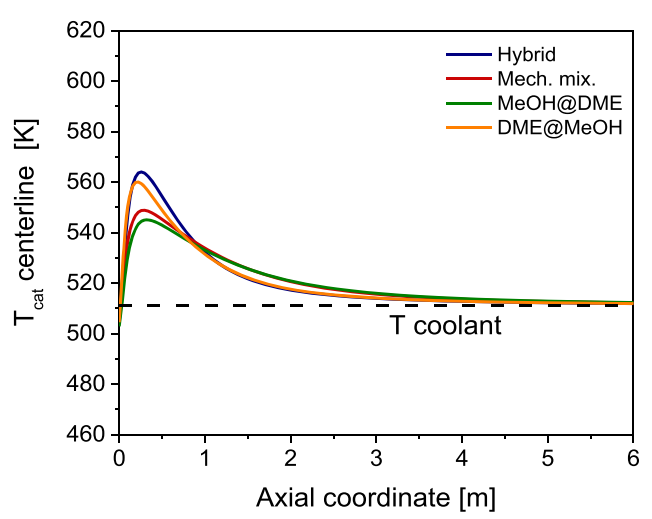

Figure 13. Catalyst temperature profile on the tube centerline with different catalyst configurations using a feed with $\mathrm{M}=2$ and $\mathrm{CO} / \mathrm{CO}_{2}$ $=1$.

for the reference composition. The highest hotspot is reached in the case of the hybrid configuration, consistently with the maximum DME yield shown in Figure 12. However, the DME@MeOH temperature profile closely follows, despite the significantly lower DME yield achieved with this configuration. On the contrary, the advantages of using the $\mathrm{MeOH} @ \mathrm{DME}$ pellet is even more evident than in the previous case: the hotspot temperature is lower than the one obtained with the mechanical mixture, while the DME yield is larger. In general, the temperatures are milder than those calculated with the feed ratio $\mathrm{CO} / \mathrm{CO}_{2}=2$ due to the lower heat duty associated with the lower $\mathrm{CO}$ feed content and the reduced extent of the WGS reaction.

3.4. Effect of Pressure. The effect of pressure is investigated in the range of 30-50 bar. The same operating conditions and reactor geometry as in the previous sections (Table 1 and case A in Table 2) are used. The same ranking of the DME yield catalyst configuration (hybrid > MeOH@DME > DME@MeOH > mechanical mixture) is maintained in the whole pressure range (Figure 14a). The DME yield increases with pressure for all of the investigated configurations, consistently with the increase of $\mathrm{CO}_{x}$ conversion (Figure $14 \mathrm{~b}$ ), which is due to an increase of the methanol synthesis reaction kinetics and the positive effect of pressure on the thermodynamic equilibrium (the methanol synthesis proceeds with a decrease of the number of moles). The $\mathrm{CO}_{x}$ conversion is always the largest in the case of the hybrid pellet configuration and the lowest in the mechanical mixture, while is almost the same using the two core@shell configurations. On the other hand, the DME selectivity decreases with the pressure (Figure 14c) since the kinetics of methanol dehydration is hindered by the increase of pressure (particularly $P_{\mathrm{H}_{2} \mathrm{O}}$ ). The DME selectivity ranking is maintained in the whole range of pressure considered, with the $\mathrm{MeOH} @$ DME being always the most selective to DME (slightly more than hybrid), while the $\mathrm{DME} @ \mathrm{MeOH}$ being the least selective one.

3.5. Effect of Methanol Synthesis/Dehydration Catalyst Ratio. The effect of the $\mathrm{MeOH} / \mathrm{DME}$ catalyst mass ratio is finally investigated in the range between $1: 4$ and $4: 1$. The 

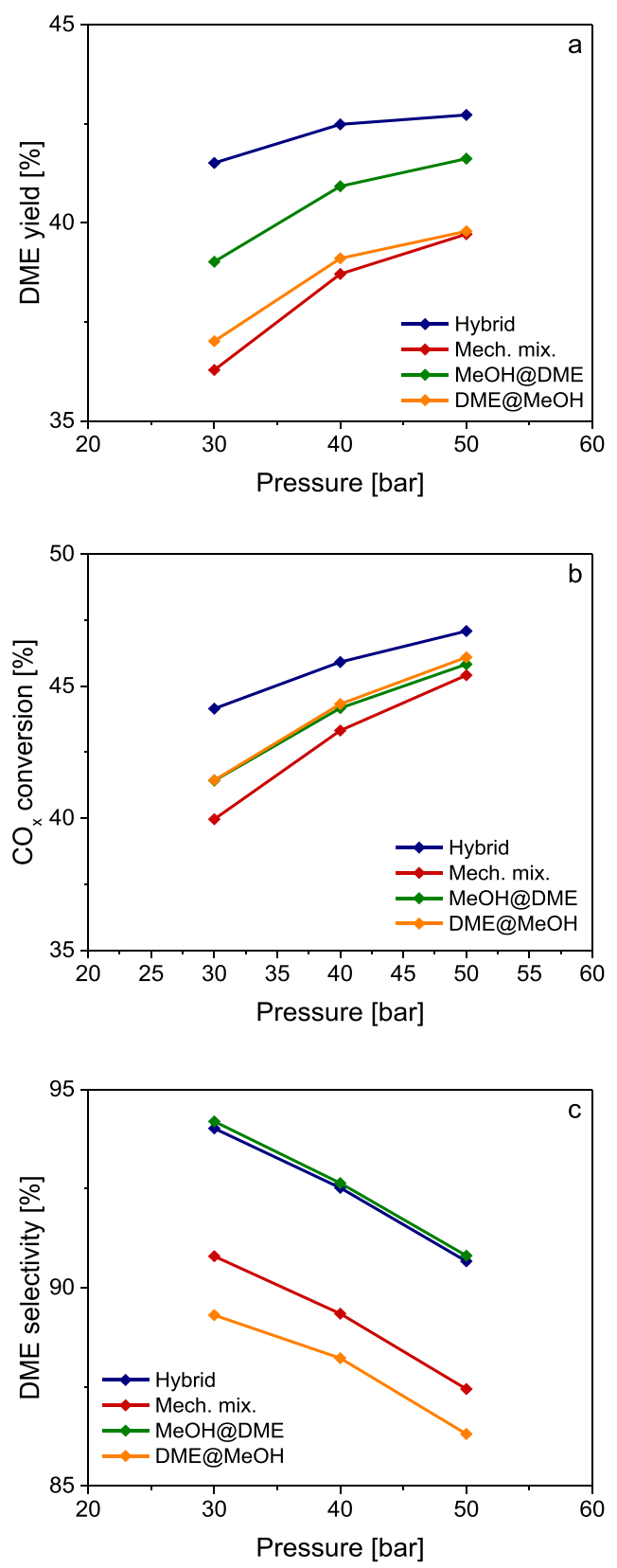

Figure 14. Effect of pressure on (a) DME yield, (b) $\mathrm{CO}_{x}$ conversion, and (c) DME carbon selectivity using different catalyst configurations.

same operating conditions and reactor geometry as in the previous section (Table 1 and case A in Table 2) are used.

The effect of the active phase distribution on the DME carbon yield is shown in Figure 15a. The hybrid pellets overperform all of the other configurations at each catalyst ratio, while the worst performance is always obtained with the mechanical mixture. The DME yield with the hybrid configuration shows a weak maximum at $1: 1$ (42.9\%) with a small decrease upon increasing $\mathrm{MeOH} / \mathrm{DME}$ catalyst ratio (41.9\% at $4: 1)$ and a slightly more pronounced drop in the other direction $(40.9 \%$ at $1: 4)$. In the case of the mechanical mixture, the yield keeps almost the same for the $1: 1$ and 2:1 ratios (39.7-39.8\%), while it markedly decreases for lower and higher ratios. The trends for the core@shell configurations are opposite: at low $\mathrm{MeOH} / \mathrm{DME}$ catalyst ratios, the yield with the MeOH@DME pellets almost overlaps with that of the
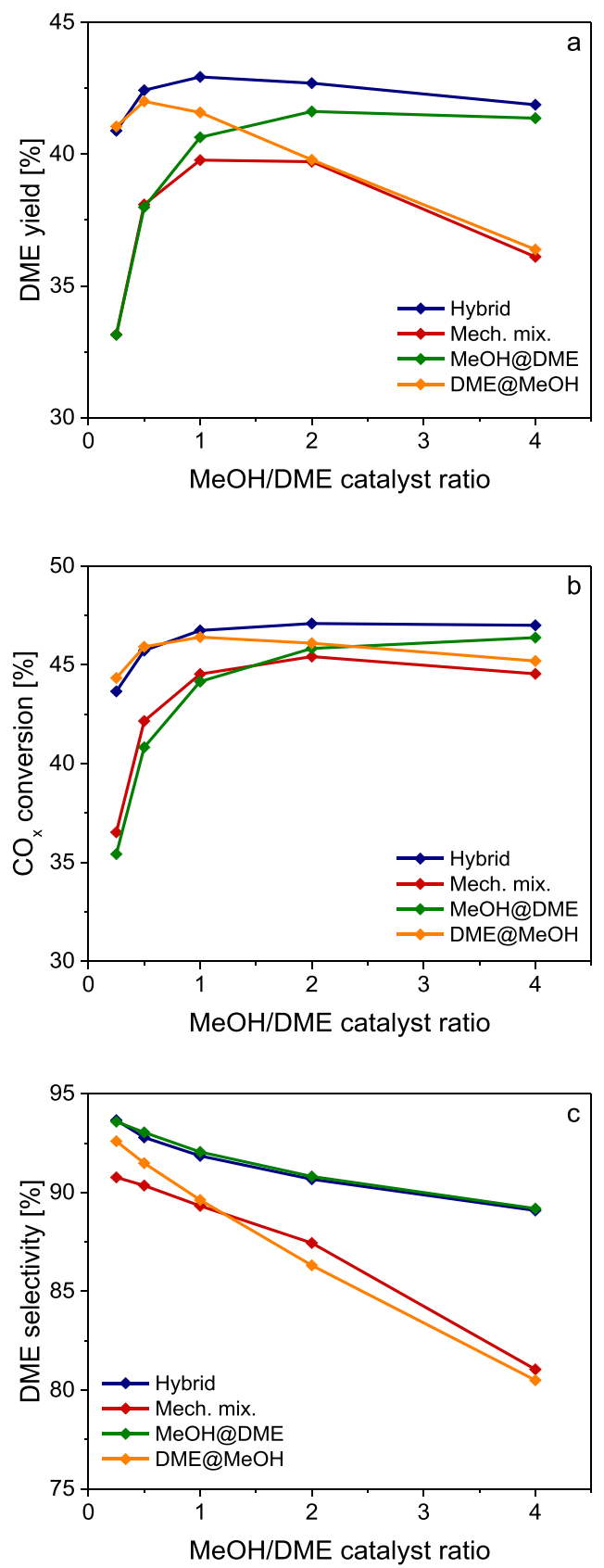

Figure 15. Effect of the $\mathrm{MeOH} / \mathrm{DME}$ catalyst ratio on (a) DME yield, (b) $\mathrm{CO}_{x}$ conversion, and (c) DME carbon selectivity using different catalyst configurations.

mechanical mixture, markedly increasing with $\mathrm{MeOH} / \mathrm{DME}$, reaching an optimum at around 2:1 (41.6\%), and slightly decreasing at $4: 1$, getting close to that of the hybrid pellets; at variance, in the case of DME@MeOH, the DME yield is the same as that of the hybrid one at low $\mathrm{MeOH} / \mathrm{DME}$ ratios, has an optimum at around 1:2 (42.0\%), and decreases overlapping with that of the mechanical mixture for ratios larger than $2: 1$.

These trends can be explained in the light of the findings reported in the previous section: the $\mathrm{MeOH} @ \mathrm{DME}$ core@ shell configuration maximizes the efficiency of the DME catalyst (and the DME selectivity), which makes the $\mathrm{MeOH}$ formation rate a limiting factor. Accordingly, the $\mathrm{CO}_{x}$ conversion (Figure 15b) increases with the $\mathrm{MeOH} / \mathrm{DME}$ catalyst ratio, compensating the slight decrease of $\mathrm{DME}$ 
selectivity (Figure 15c), resulting in the optimum $\mathrm{MeOH} /$ $\mathrm{DME}$ at $2: 1$. On the other hand, the DME@MeOH configuration maximizes the methanol formation rate, causing the methanol dehydration to become the limiting step at a $\mathrm{MeOH} / \mathrm{DME}$ ratio of $1: 1$. As a result, the $\mathrm{CO}_{\mathrm{x}}$ conversion shows a maximum at $1: 1$, which combined with the monotonic decrease of DME selectivity results in the optimum $\mathrm{MeOH} /$ DME ratio of around 1:2.

The effect of the $\mathrm{MeOH} / \mathrm{DME}$ catalyst ratio on the hotspot temperature is shown in Figure 16. In the investigated range,

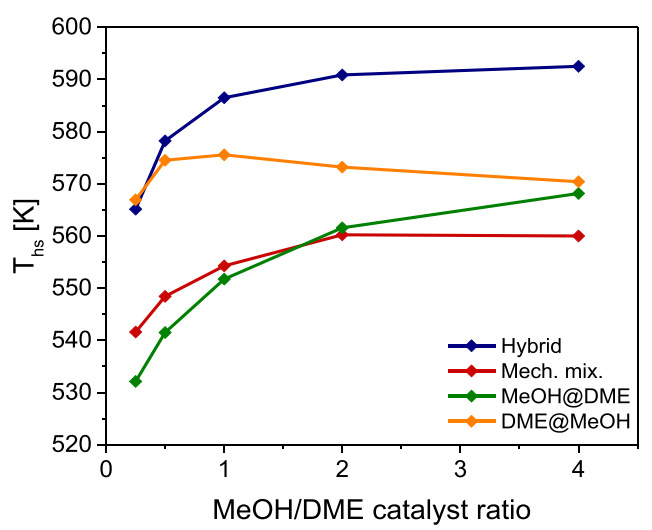

Figure 16. Effect of the $\mathrm{MeOH} / \mathrm{DME}$ catalyst ratio on catalyst centerline temperature hotspot using different catalyst configurations.

the highest hotspot temperature is obtained with the hybrid pellets due to the largest $\mathrm{CO}_{x}$ conversion (Figure 15b) and the consequent maximum heat release. With the hybrid pellet configuration, the hotspot increases upon increasing $\mathrm{MeOH} /$ DME catalyst ratio as a consequence of (i) the volumetric rate of methanol formation, which grows with the fraction of the $\mathrm{MeOH}$ catalyst in the hybrid pellets, and (ii) the exothermicity of methanol synthesis, which is higher than that of methanol dehydration.

The DME@MeOH core@shell catalyst shows the opposite trend of the hotspot temperature, which, except at 1:4, decreases with the $\mathrm{MeOH} / \mathrm{DME}$ catalyst ratio consistently and the progressive decrease of the reactant conversion. In this case, in fact, the dehydration step becomes so limiting to slow down also the methanol formation rate due to the onset of thermodynamic constraints. It is worth noting that with catalyst ratios 1:2 and 1:4, the DME@MeOH has almost the same hotspot temperature as the hybrid configuration, consistently with very close conversion performances. On the other hand, the expected trend, i.e., hotspot temperature increasing with the $\mathrm{MeOH} / \mathrm{DME}$ catalyst ratio, is observed for both the MeOH@DME core@shell configuration and the mechanical mixture.

It is worth noting that the high methanol formation rate makes the hotspot temperature in the DME@MeOH configuration higher $(15-25 \mathrm{~K})$ than that obtained with $\mathrm{MeOH} @ \mathrm{DME}$ in the whole investigated range and particularly at low $\mathrm{MeOH} / \mathrm{DME}$ catalyst ratios.

\section{CONCLUSIONS}

A model analysis of the effects of active phase distribution at the pellet scale (hybrid pellets, mechanical mixtures of pellets, MeOH@DME and DME@MeOH core@shell pellets) in catalytic reactors for the direct dimethyl ether synthesis is performed. The simulation of an externally cooled multitubular packed bed reactor is made using a $2 \mathrm{D}+1 \mathrm{D}$ heterogeneous model of a single reactor tube to carefully address the heat transfer behavior in the presence of a strongly exothermic process and the impact of intraparticle diffusion phenomena on pellets of the industrial size. Benchmark catalyst formulations, CZA for methanol synthesis and $\gamma-\mathrm{Al}_{2} \mathrm{O}_{3}$ for methanol dehydration, are considered.

The analysis shows that both the methanol synthesis and dehydration reactions are strongly constrained by the internal diffusion, which limits the DME yield in the case of mechanical mixtures of methanol synthesis and methanol dehydration pellets. A hybrid pellet configuration minimizes the diffusion length between methanol synthesis and methanol dehydration active phases, thus ensuring a faster reactant conversion and a higher DME yield. However, the faster reactivity leads to higher hot-spots in the reactor, which might exceed the critical temperature for CZA sintering. Besides, deactivation phenomena have been reported in the literature for hybrid pellets due to the intimate contact of the two active phases. ${ }^{27}$ The core@ shell catalyst configurations, which reduce both the diffusion lengths and the contact surface between methanol and dehydration active phases, have been shown to provide higher DME yield than the mechanical mixture with lower hotspot temperature than the hybrid pellet configuration. In particular, simulation results show that the MeOH@DME catalyst is the most promising, providing the maximum selectivity to DME, which brings the DME yield comparable to that of the hybrid catalyst while allowing to operate with hotspot temperatures almost $30 \mathrm{~K}$ lower than those of the hybrid catalyst. Similar calculated trends are obtained when changing the pressure and syngas feed composition.

On the other hand, due to the complex reaction/diffusion interplay, the active phase distribution markedly affects the optimum weight ratio of the methanol synthesis to methanol dehydration catalyst. DME@MeOH core@shell pellets require lower relative amounts of CZA methanol synthesis catalysts than $\mathrm{MeOH} @ \mathrm{DME}$ ones. Specifically, optimum $\mathrm{MeOH} / \mathrm{DME}$ catalyst ratios equal to $1: 2$ and $2: 1$ are found for the former and the latter pellet configuration, respectively.

These results, considered together with the experimental evidence reported in the literature ${ }^{42,43}$ on the improved stability of core@shell catalysts, are promising in view of the development of intensified processes for the direct DME synthesis.

\section{ASSOCIATED CONTENT}

\section{SI Supporting Information}

The Supporting Information is available free of charge at https://pubs.acs.org/doi/10.1021/acs.iecr.0c01938.

Kinetic equation parameters, physicochemical properties and transport correlations, discretization grid, and diffusion model comparison-Fick vs dusty-gas model (PDF)

\section{AUTHOR INFORMATION}

\section{Corresponding Author}

Gianpiero Groppi - Laboratory of Catalysis and Catalytic Processes, Dipartimento di Energia, Politecnico di Milano, 20156 Milano, Italy; (1) orcid.org/0000-0001-8099-580X; Email: gianpiero.groppi@polimi.it 


\section{Authors}

Simone Guffanti - Laboratory of Catalysis and Catalytic Processes, Dipartimento di Energia, Politecnico di Milano, 20156 Milano, Italy; @ orcid.org/0000-0002-5657-3954

Carlo Giorgio Visconti - Laboratory of Catalysis and Catalytic Processes, Dipartimento di Energia, Politecnico di Milano, 20156 Milano, Italy; 이이. orcid.org/0000-0001-5205-982X

Complete contact information is available at:

https://pubs.acs.org/10.1021/acs.iecr.0c01938

\section{Notes}

The authors declare no competing financial interest.

\section{ACKNOWLEDGMENTS}

This work has received funding from the European Union's Horizon 2020 Research and Innovation Programme under grant agreement no. 727600 .

\section{NOTATION}

$a_{\mathrm{v}} \quad$ solid specific surface area per unit volume $\left(\mathrm{m}^{2} / \mathrm{m}^{3}\right)$

$B_{0} \quad$ effective catalyst permeability $\left(\mathrm{m}^{2}\right)$

$C_{\mathrm{p}, \mathrm{g}} \quad$ gas mixture specific heat $(\mathrm{J} / \mathrm{kg} / \mathrm{K})$

$C_{\mathrm{s}, i} \quad$ molar concentration of species $i$ in the catalyst pellet $\left(\mathrm{mol} / \mathrm{m}^{3}\right)$

$C_{\text {surf }, i}$ molar concentration of species $i$ on the catalyst pellet surface $\left(\mathrm{mol} / \mathrm{m}^{3}\right)$

$d_{\mathrm{p}} \quad$ diameter of the spherical catalyst pellet $(\mathrm{m})$

$d_{\mathrm{t}} \quad$ tube diameter $(\mathrm{m})$

$D_{\text {eff }, i}$ effective diffusion coefficient of species $i$ in the solid catalyst $\left(\mathrm{m}^{2} / \mathrm{s}\right)$

$D_{\text {er }, i} \quad$ effective radial diffusivity of species $i\left(\mathrm{~m}^{2} / \mathrm{s}\right)$

$D_{i j} \quad$ binary diffusion coefficient of species $i$ in species $j\left(\mathrm{~m}^{2} /\right.$ s)

$D_{\mathrm{k}, i} \quad$ Knudsen diffusion coefficient of species $i\left(\mathrm{~m}^{2} / \mathrm{s}\right)$

$D_{\text {mix }, i}$ molecular diffusion coefficient of species $i\left(\mathrm{~m}^{2} / \mathrm{s}\right)$

$f_{i} \quad$ fugacity of species $i$ (bar)

$f_{\mathrm{m}} \quad$ friction factor $(-)$

$F_{i} \quad$ molar flow rate of species $i(\mathrm{~mol} / \mathrm{s})$

$h_{\mathrm{gs}}$ gas-solid heat transfer coefficient $\left(\mathrm{W} / \mathrm{m}^{2} / \mathrm{K}\right)$

$h_{\mathrm{w}} \quad$ wall heat transfer coefficient $\left(\mathrm{W} / \mathrm{m}^{2} / \mathrm{K}\right)$

$h_{\mathrm{w}, \text { conv }}$ convective heat transfer coefficient $\left(\mathrm{W} / \mathrm{m}^{2} / \mathrm{K}\right)$

$J_{i}$ diffusional flux of species $i\left(\mathrm{~mol} / \mathrm{m}^{2} / \mathrm{s}\right)$

$k_{j} \quad$ kinetic (rate) constant of reaction $j$

$K_{\text {eq } j} \quad$ equilibrium constant of reaction $j$

$\mathrm{K}_{i}$ adsorption equilibrium constant of species $i$ on the catalyst

$K_{\mathrm{m}, i}$ gas-solid mass transfer coefficient of species $i(\mathrm{~m} / \mathrm{s})$

$L_{\mathrm{t}} \quad$ tube length $(\mathrm{m})$

$\mathrm{MW}_{\mathrm{g}}$ gas mixture molar weight $(\mathrm{kg} / \mathrm{mol})$

$\mathrm{MW}_{i}$ molar weight of species $i(\mathrm{~kg} / \mathrm{mol})$

NC number of components (-)

NR number of reactions (-)

$\mathrm{Nu} \quad$ Nusselt number (-)

$P$ pressure $(\mathrm{Pa})$

$\mathrm{Pr} \quad$ Prandtl number (-)

$R \quad$ reactor radial coordinate $(\mathrm{m})$

$r_{\text {int }} \quad$ core@shell pellet interface radius (m)

$r_{\mathrm{p}} \quad$ catalyst pellet radius $(\mathrm{m})$

$R$ universal gas constant $(\mathrm{J} / \mathrm{mol} / \mathrm{K})$

$R_{j} \quad$ rate of reaction $j(\mathrm{~mol} / \mathrm{kg} / \mathrm{s})$

$R e_{\mathrm{dp}} \quad$ Reynolds number of a pellet particle with diameter $d_{\mathrm{p}}$ (m)
$S_{\mathrm{p}} \quad$ catalyst pellet geometrical surface area $\left(\mathrm{m}^{2}\right)$

$S c \quad$ Schmidt number (-)

Sh Sherwood number (-)

$T$ temperature $(\mathrm{K})$

$v \quad$ gas velocity $(\mathrm{m} / \mathrm{s})$

$\mathrm{V} / \mathrm{S}$ diffusion length $(\mathrm{mm})$

$V_{\mathrm{p}} \quad$ catalyst pellet volume $\left(\mathrm{m}^{3}\right)$

$W_{\mathrm{t}}$ mass flow rate per unit area $\left(\mathrm{kg} / \mathrm{m}^{2} / \mathrm{s}\right)$

$x \quad$ pellet radial coordinate $(\mathrm{m})$

$y_{i} \quad$ molar fraction of species $i(-)$

$Y_{\mathrm{DME}}$ dimethyl ether carbon yield $(-)$

$z \quad$ reactor axial coordinate $(\mathrm{m})$

\section{GREEK LETTERS}

$\Delta H_{\mathrm{r}, j}$ heat of reaction $j(\mathrm{~J} / \mathrm{mol})$

$\varepsilon \quad$ bed void fraction $(-)$

$\varepsilon_{\mathrm{p}} \quad$ catalyst porosity (-)

$\eta_{j, k} \quad$ catalyst effectiveness factor of reaction $j$ for the catalyst $k(-)$

$\lambda_{\text {eff,r }}$ effective radial thermal conductivity $(\mathrm{W} / \mathrm{m} / \mathrm{K})$

$\lambda_{\mathrm{g}} \quad$ gas mixture thermal conductivity $(\mathrm{W} / \mathrm{m} / \mathrm{K})$

$\lambda_{\mathrm{s}} \quad$ solid catalyst thermal conductivity $(\mathrm{W} / \mathrm{m} / \mathrm{K})$

$\mu_{\mathrm{g}} \quad$ gas mixture viscosity $(\mathrm{kg} / \mathrm{m} / \mathrm{s})$

$\nu_{i j} \quad$ stoichiometric coefficient of species $i$ in reaction $j(-)$

$\xi_{k} \quad$ volumetric fraction of catalyst $k(-)$

$\rho_{\mathrm{g}} \quad$ gas mixture density $\left(\mathrm{kg} / \mathrm{m}^{3}\right)$

$\rho_{\mathrm{s}, k} \quad$ solid catalyst bulk density $\left(\mathrm{kg} / \mathrm{m}^{3}\right)$

$\tau \quad$ catalyst tortuosity (-)

$v_{i} \quad$ diffusional volume of species $i\left(\mathrm{~cm}^{3} / \mathrm{mol}\right)$

$\omega_{i} \quad$ mass fraction of species $i(-)$

$\omega_{\text {surf }, i}$ mass fraction of species $i$ in the catalyst surface phase $(-)$

\section{SUPERSCRIPTS AND SUBSCRIPTS}

0 reactor inlet condition

av average

eff effective

cool coolant

g gas phase

hs hotspot

$i \quad i$-species $\left(i=\mathrm{CO}, \mathrm{CO}_{2}, \mathrm{H}_{2}, \mathrm{H}_{2} \mathrm{O}, \mathrm{MeOH}, \mathrm{DME}, \mathrm{CH}_{4}\right)$

$j \quad j$-reaction

$k \quad k$-catalyst phase $(k=\mathrm{MeOH}, \mathrm{DME})$

ov overall

s solid phase

\section{REFERENCES}

(1) Good, D. A.; Francisco, J. S.; Jain, A. K.; Wuebbles, D. J. Lifetimes and Global Warming Potentials for Dimethyl Ether and for Fluorinated Ethers: CH3OCF3 (E143a), $\mathrm{CHF}_{2} \mathrm{OCHF}_{2}$ (E134), $\mathrm{CHF}_{2} \mathrm{OCF}_{3}$ (E125). J. Geophys. Res.: Atmos. 1998, 103, 2818128186.

(2) Semelsberger, T. A.; Borup, R. L.; Greene, H. L. Dimethyl Ether (DME) as an Alternative Fuel. J. Power Sources 2006, 156, 497-511.

(3) Bhattacharya, S.; Kabir, K. B.; Hein, K. Dimethyl Ether Synthesis from Victorian Brown Coal through Gasification - Current Status, and Research and Development Needs. Prog. Energy Combust. Sci. 2013, 39, 577-605.

(4) Marchionna, M.; Patrini, R.; Sanfilippo, D.; Migliavacca, G. Fundamental Investigations on Di-Methyl Ether (DME) as LPG Substitute or Make-up for Domestic Uses. Fuel Process. Technol. 2008, $89,1255-1261$. 
(5) Anggarani, R.; Wibowo, C. S.; Rulianto, D. Application of Dimethyl Ether as LPG Substitution for Household Stove. Energy Procedia 2014, 47, 227-234.

(6) Arcoumanis, C.; Bae, C.; Crookes, R.; Kinoshita, E. The Potential of Di-Methyl Ether (DME) as an Alternative Fuel for Compression-Ignition Engines: A Review. Fuel 2008, 87, 1014-1030.

(7) Park, S. H.; Lee, C. S. Applicability of Dimethyl Ether (DME) in a Compression Ignition Engine as an Alternative Fuel. Energy Convers. Manage. 2014, 86, 848-863.

(8) Takeishi, K.; Suzuki, H. Steam Reforming of Dimethyl Ether. Appl. Catal., A 2004, 260, 111-117.

(9) Semelsberger, T. A.; Borup, R. L. Thermodynamic Equilibrium Calculations of Dimethyl Ether Steam Reforming and Dimethyl Ether Hydrolysis. J. Power Sources 2005, 152, 87-96.

(10) Semelsberger, T. A.; Ott, K. C.; Borup, R. L.; Greene, H. L. Generating Hydrogen-Rich Fuel-Cell Feeds from Dimethyl Ether (DME) Using Physical Mixtures of a Commercial $\mathrm{Cu} / \mathrm{Zn} / \mathrm{Al}_{2} \mathrm{O}_{3}$ Catalyst and Several Solid-Acid Catalysts. Appl. Catal., B 2006, 65, 291-300.

(11) Cocco, D.; Tola, V.; Cau, G. Performance Evaluation of Chemically Recuperated Gas Turbine (CRGT) Power Plants Fuelled by Di-Methyl-Ether (DME). Energy 2006, 31, 1446-1458.

(12) Lee, M. C.; Seo, S. B.; Chung, J. H.; Joo, Y. J.; Ahn, D. H. Industrial Gas Turbine Combustion Performance Test of DME to Use as an Alternative Fuel for Power Generation. Fuel 2009, 88, 657662.

(13) Pérez-Uriarte, P.; Ateka, A.; Aguayo, A. T.; Gayubo, A. G.; Bilbao, J. Kinetic Model for the Reaction of DME to Olefins over a HZSM-5 Zeolite Catalyst. Chem. Eng. J. 2016, 302, 801-810.

(14) Pérez-Uriarte, P.; Ateka, A.; Gamero, M.; Aguayo, A. T.; Bilbao, J. Effect of the Operating Conditions in the Transformation of DME to Olefins over a HZSM-5 Zeolite Catalyst. Ind. Eng. Chem. Res. 2016, $55,6569-6578$.

(15) Azizi, Z.; Rezaeimanesh, M.; Tohidian, T.; Rahimpour, M. R. Dimethyl Ether: A Review of Technologies and Production Challenges. Chem. Eng. Process. Process Intensif. 2014, 82, 150-172.

(16) Dadgar, F.; Myrstad, R.; Pfeifer, P.; Holmen, A.; Venvik, H. J. Direct Dimethyl Ether Synthesis from Synthesis Gas: The Influence of Methanol Dehydration on Methanol Synthesis Reaction. Catal. Today 2016, 270, 76-84.

(17) Ateka, A.; Pérez-Uriarte, P.; Gamero, M.; Ereña, J.; Aguayo, A. T.; Bilbao, J. A Comparative Thermodynamic Study on the $\mathrm{CO}_{2}$ Conversion in the Synthesis of Methanol and of DME. Energy 2017, 120, 796-804.

(18) De Falco, M.; Capocelli, M.; Centi, G. Dimethyl Ether Production from $\mathrm{CO}_{2}$ Rich Feedstocks in a One-Step Process: Thermodynamic Evaluation and Reactor Simulation. Chem. Eng. J. 2016, 294, 400-409.

(19) Saravanan, K.; Ham, H.; Tsubaki, N.; Bae, J. W. Recent Progress for Direct Synthesis of Dimethyl Ether from Syngas on the Heterogeneous Bifunctional Hybrid Catalysts. Appl. Catal., B 2017, 217, 494-522.

(20) Lee, S. B.; Cho, W.; Park, D. K.; Yoon, E. S. Simulation of Fixed Bed Reactor for Dimethyl Ether Synthesis. Korean J. Chem. Eng. 2006, 23, 522-530.

(21) Song, D.; Cho, W.; Park, D. K.; Yoon, E. S. Comparison of the Performance of a Fixed Bed Reactor in the Two Cases, Mixture of Catalyst Pellets and a Hybrid Catalyst, for Dimetyl Ether Synthesis. J. Ind. Eng. Chem. 2007, 13, 815-826.

(22) Song, D.; Cho, W.; Lee, G.; Park, D. K.; Yoon, E. S. Numerical Analysis of a Pilot-Scale Fixed-Bed Reactor for Dimethyl Ether (DME) Synthesis. Ind. Eng. Chem. Res. 2008, 47, 4553-4559.

(23) Klier, K. Methanol synthesis. Adv. Catal. 1982, 31, 243-313.

(24) Spivey, J. J. Review: Dehydration Catalysts for the Methanol/ Dimethyl Ether Reaction. Chem. Eng. Commun. 1991, 110, 123-142.

(25) Li, J. L.; Zhang, X. G.; Inui, T. Improvement in the Catalyst Activity for Direct Synthesis of Dimethyl Ether from Synthesis Gas through Enhancing the Dispersion of $\mathrm{CuO} / \mathrm{ZnO} / \gamma-\mathrm{Al}_{2} \mathrm{O}_{3}$ in Hybrid Catalysts. Appl. Catal., A 1996, 147, 23-33.
(26) García-Trenco, A.; Vidal-Moya, A.; Martínez, A. Study of the Interaction between Components in Hybrid CuZnAl/HZSM-5 Catalysts and Its Impact in the Syngas-to-DME Reaction. Catal. Today 2012, 179, 43-51.

(27) Voss, B.; Katerinopoulou, A.; Montesano, R.; Sehested, J. Zn and $\mathrm{Si}$ Transport in Dual-Functioning Catalyst for Conversion of Synthesis Gas to Dimethyl Ether. Chem. Eng. J. 2019, 377, No. 121940.

(28) Yoo, K. S.; Kim, J. H.; Park, M. J.; Kim, S. J.; Joo, O. S.; Jung, K. D. Influence of Solid Acid Catalyst on DME Production Directly from Synthesis Gas over the Admixed Catalyst of $\mathrm{Cu} / \mathrm{ZnO} / \mathrm{Al}_{2} \mathrm{O}_{3}$ and Various SAPO Catalysts. Appl. Catal., A 2007, 330, 57-62.

(29) Abu-Dahrieh, J.; Rooney, D.; Goguet, A.; Saih, Y. Activity and Deactivation Studies for Direct Dimethyl Ether Synthesis Using CuO$\mathrm{ZnO}-\mathrm{Al}_{2} \mathrm{O}_{3}$ with NH4ZSM-5, HZSM-5 or $\gamma-\mathrm{Al}_{2} \mathrm{O}_{3}$. Chem. Eng. J. 2012, 203, 201-211.

(30) García-Trenco, A.; Valencia, S.; Martínez, A. The Impact of Zeolite Pore Structure on the Catalytic Behavior of $\mathrm{CuZnAl} /$ Zeolite Hybrid Catalysts for the Direct DME Synthesis. Appl. Catal., A 2013, $468,102-111$.

(31) García-Trenco, A.; Martínez, A. The Influence of Zeolite Surface-Aluminum Species on the Deactivation of CuZnAl/Zeolite Hybrid Catalysts for the Direct DME Synthesis. Catal. Today 2014, 227, 144-153.

(32) Ordomsky, V. V.; Cai, M.; Sushkevich, V.; Moldovan, S.; Ersen, O.; Lancelot, C.; Valtchev, V.; Khodakov, A. Y. The Role of External Acid Sites of ZSM-5 in Deactivation of Hybrid CuZnAl/ZSM-5 Catalyst for Direct Dimethyl Ether Synthesis from Syngas. Appl. Catal., A 2014, 486, 266-275.

(33) Morbidelli, M.; Gavriilidis, A.; Varma, A. Catalyst Design: Optimal Distribution of Catalyst in Pellets, Reactors, and Membranes; Cambridge University Press, 2005.

(34) Yang, G.; Tsubaki, N.; Shamoto, J.; Yoneyama, Y.; Zhang, Y. Confinement Effect and Synergistic Function of H-ZSM-5/Cu-ZnO$\mathrm{Al}_{2} \mathrm{O}_{3}$ Capsule Catalyst for One-Step Controlled. J. Am. Chem. Soc. 2010, 132, 8129-8136.

(35) Yang, G.; Thongkam, M.; Vitidsant, T.; Yoneyama, Y.; Tan, Y.; Tsubaki, N. A Double-Shell Capsule Catalyst with Core-Shell-like Structure for One-Step Exactly Controlled Synthesis of Dimethyl Ether from $\mathrm{CO}_{2}$ Containing Syngas. Catal. Today 2011, 171, 229235.

(36) Nie, R.; Lei, H.; Pan, S.; Wang, L.; Fei, J.; Hou, Z. Core-Shell Structured CuO-ZnO@H-ZSM-5 Catalysts for CO Hydrogenation to Dimethyl Ether. Fuel 2012, 96, 419-425.

(37) Pinkaew, K.; Yang, G.; Vitidsant, T.; Jin, Y.; Zeng, C.; Yoneyama, Y.; Tsubaki, N. A New Core-Shell-like Capsule Catalyst with SAPO-46 Zeolite Shell Encapsulated $\mathrm{Cr} / \mathrm{ZnO}$ for the Controlled Tandem Synthesis of Dimethyl Ether from Syngas. Fuel 2013, 111, $727-732$.

(38) Sun, J.; Yang, G.; Yoneyama, Y.; Tsubaki, N. Catalysis Chemistry of Dimethyl Ether Synthesis. ACS Catal. 2014, 4, 33463356.

(39) Wang, Y.; Wang, W.; Chen, Y.; Ma, J.; Li, R. Synthesis of Dimethyl Ether from Syngas over Core-Shell Structure Catalyst $\mathrm{CuO}$ $\mathrm{ZnO}-\mathrm{Al}_{2} \mathrm{O}_{3} @ \mathrm{SiO}_{2}-\mathrm{Al}_{2} \mathrm{O}_{3}$. Chem. Eng. J. 2014, 250, 248-256.

(40) Ding, W.; Klumpp, M.; Lee, S.; Reuß, S.; Al-Thabaiti, S. A.; Pfeifer, P.; Schwieger, W.; Dittmeyer, R. Simulation of One-Stage Dimethyl Ether Synthesis over a Core-Shell Catalyst. Chem. Ing. Tech. 2015, 87, 702-712.

(41) Liu, R.; Tian, H.; Yang, A.; Zha, F.; Ding, J.; Chang, Y. Preparation of HZSM-5 Membrane Packed CuO-ZnO- $\mathrm{Al}_{2} \mathrm{O}_{3}$ Nanoparticles for Catalysing Carbon Dioxide Hydrogenation to Dimethyl Ether. Appl. Surf. Sci. 2015, 345, 1-9.

(42) Baier, S.; Damsgaard, C. D.; Klumpp, M.; Reinhardt, J.; Sheppard, T.; Balogh, Z.; Kasama, T.; Benzi, F.; Wagner, J. B.; Schwieger, W.; Schroer, C. G.; Grunwaldt, J. D. Stability of a Bifunctional Cu-Based Core@Zeolite Shell Catalyst for Dimethyl Ether Synthesis under Redox Conditions Studied by Environmental 
Transmission Electron Microscopy and in Situ X-Ray Ptychography. Microsc. Microanal. 2017, 23, 501-512.

(43) Sánchez-Contador, M.; Ateka, A.; Aguayo, A. T.; Bilbao, J. Direct Synthesis of Dimethyl Ether from $\mathrm{CO}$ and $\mathrm{CO}_{2}$ over a CoreShell Structured CuO-ZnO-ZrO ${ }_{2} @ S A P O-11$ Catalyst. Fuel Process. Technol. 2018, 179, 258-268.

(44) Sánchez-Contador, M.; Ateka, A.; Ibáñez, M.; Bilbao, J.; Aguayo, A. T. Influence of the Operating Conditions on the Behavior and Deactivation of a CuO-ZnO-ZrO $\mathrm{ZSSAPO}_{2}$-11 Core-Shell-like Catalyst in the Direct Synthesis of DME. Renewable Energy 2019, 138, 585-597.

(45) Hu, Y.; Nie, Z.; Fang, D. Simulation and Model Design of PipeShell Reactor for the Direct Synthesis of Dimethyl Ether from Syngas. J. Nat. Gas Chem. 2008, 17, 195-200.

(46) Yoon, E. S.; Han, C. A Review of Sustainable Energy - Recent Development and Future Prospects of Dimethyl Ether (DME). Comput.-Aided Chem. Eng. 2009, 27, 169-175.

(47) Peláez, R.; Marín, P.; Díez, F. V.; Ordóñez, S. Direct Synthesis of Dimethyl Ether in Multi-Tubular Fixed-Bed Reactors: 2D MultiScale Modelling and Optimum Design. Fuel Process. Technol. 2018, 174, 149-157.

(48) Yagi, H.; Ohno, Y.; Inoue, N.; Okuyama, K.; Aoki, S. Slurry Phase Reactor Technology for DME Direct Synthesis Int. J. Chem. React. Eng. 2010, 8, DOI: 10.2202/1542-6580.2267.

(49) Ohno, Y.; Yagi, H.; Inoue, N.; Okuyama, K.; Aoki, S. Slurry Phase DME Direct Synthesis Technology -100 Tons/Day Demonstration Plant Operation and Scale up Study-. Stud. Surf. Sci. Catal. 2007, 167, 403-408.

(50) Ogawa, T.; Inoue, N.; Shikada, T.; Ohno, Y. Direct Dimethyl Ether Synthesis. J. Nat. Gas Chem. 2003, 12, 219-227.

(51) Papari, S.; Kazemeini, M.; Fattahi, M. Mathematical Modeling of a Slurry Reactor for DME Direct Synthesis from Syngas. J. Nat. Gas Chem. 2012, 21, 148-157.

(52) Lu, W. Z.; Teng, L. H.; Xiao, W.-D. Simulation and Experiment Study of Dimethyl Ether Synthesis from Syngas in a Fluidized-Bed Reactor. Chem. Eng. Sci. 2004, 59, 5455-5464.

(53) Hayer, F.; Bakhtiary-Davijany, H.; Myrstad, R.; Holmen, A.; Pfeifer, P.; Venvik, H. J. Synthesis of Dimethyl Ether from Syngas in a Microchannel Reactor-Simulation and Experimental Study. Chem. Eng. J. 2011, 167, 610-615.

(54) Hayer, F.; Bakhtiary-Davijany, H.; Myrstad, R.; Holmen, A.; Pfeifer, P.; Venvik, H. J. Modeling and Simulation of an Integrated Micro Packed Bed Reactor-Heat Exchanger Configuration for Direct Dimethyl Ether Synthesis. Top. Catal. 2011, 54, 817-827.

(55) Hayer, F.; Bakhtiary-Davijany, H.; Myrstad, R.; Holmen, A.; Pfeifer, P.; Venvik, H. J. Characteristics of Integrated Micro Packed Bed Reactor-Heat Exchanger Configurations in the Direct Synthesis of Dimethyl Ether. Chem. Eng. Process. Process Intensif. 2013, 70, 7785 .

(56) Venvik, H. J.; Yang, J. Catalysis in Microstructured Reactors: Short Review on Small-Scale Syngas Production and Further Conversion into Methanol, DME and Fischer-Tropsch Products. Catal. Today 2017, 285, 135-146.

(57) Krishna, R.; Wesselingh, J. A. The Maxwell-Stefan Approach to Mass Transfer. Science 1997, 52, 861-911.

(58) Skrzypek, J.; Grzesik, M.; Szopa, R. Theoretical Analysis of Two Parallel and Consecutive Reactions in Isothermal Symmetrical Catalyst Pellets Using the Dusty-Gas Model. Chem. Eng. Sci. 1984, $39,515-521$.

(59) Graaf, G. H.; Scholtens, H.; Stamhuis, E. J.; Beenackers, A. A. C. M. Intra-Particle Diffusion Limitations in Low-Pressure Methanol Synthesis. Chem. Eng. Sci. 1990, 45, 773-783.

(60) Lommerts, B. J.; Graaf, G. H.; Beenackers, A. A. C. M. Mathematical Modeling of Internal Mass Transport Limitations in Methanol Synthesis. Chem. Eng. Sci. 2000, 55, 5589-5598.

(61) Rout, K. R.; Hillestad, M.; Jakobsen, H. A. A Numerical Study of Pellet Model Consistency with Respect to Molar and Mass Average Velocities, Pressure Gradients and Porosity Models for Methanol
Synthesis Process: Effects of Flux Models on Reactor Performance. Chem. Eng. Res. Des. 2013, 91, 296-317.

(62) Ng, K. L.; Chadwick, D.; Toseland, B. A. Kinetics and Modelling of Dimethyl Ether Synthesis from Synthesis Gas. Chem. Eng. Sci. 1999, 54, 3587-3592.

(63) Vanden Bussche, K. M.; Froment, G. F. A Steady-State Kinetic Model for Methanol Synthesis and the Water Gas Shift Reaction on a Commercial $\mathrm{Cu} / \mathrm{ZnO} / \mathrm{Al}_{2} \mathrm{O}_{3}$ Catalyst. J. Catal. 1996, 161, 1-10.

(64) Berčič, G.; Levec, J. Intrinsic and Global Reaction Rate of Methanol Dehydration over $\gamma-\mathrm{Al}_{2} \mathrm{O}_{3}$ Pellets. Ind. Eng. Chem. Res. 1992, 31, 1035-1040.

(65) Berčič, G.; Levec, J. Catalytic Dehydration of Methanol to Dimethyl Ether. Kinetic Investigation and Reactor Simulation. Ind. Eng. Chem. Res. 1993, 32, 2478-2484.

(66) Herman, R. G.; Klier, K.; Simmons, G. W.; Finn, B. P.; Bulko, J. B.; Kobylinski, T. P. Catalytic Synthesis of Methanol from CO/ $\mathrm{H}_{2}$. I. Phase Composition, Electronic Properties and Activity of the $\mathrm{Cu}$ / $\mathrm{ZnO} / \mathrm{M}_{2} \mathrm{O}_{3}$ Catalysts. Preprints 1978, 23, 595-615.

(67) Vesovic, V. Predicting the Viscosity of Natural Gas. Int. J. Thermophys. 2001, 22, 415-426.

(68) Poling, B. E.; Prausnitz, J. M.; O'Connell, J. P. The Properties of Gases and Liquids, 5th ed.; McGraw-Hill, 2001.

(69) Fuller, E. N.; Ensley, K.; Giddings, J. C. Diffusion of Halogenated Hydrocarbons in Helium. The Effect of Structure on Collision Cross Sections. J. Phys. Chem. A. 1969, 73, 3679-3685.

(70) Bosanquet, C. H. British TA Report BR-507, 1944.

(71) Wakao, N.; Funazkri, T. Effect of Fluid Dispersion Coefficients on Particle-to-Fluid Mass Transfer Coefficients in Packed Beds. Correlation of Sherwood Numbers. Chem. Eng. Sci. 1978, 33, 13751384.

(72) Pfeffer, R. Heat and Mass Transport in Multiparticle Systems. Ind. Eng. Chem. Fundam. 1964, 3, 380-383.

(73) Specchia, V.; Sicardi, S. Modified Correlation for the Conductive Contribution of Thermal Conductivity in Packed Bed Reactors. Chem. Eng. Commun. 1980, 6, 131-139.

(74) Specchia, V.; Baldi, G.; Sicardi, S. Heat Transfer in Packed Bed Reactors with One Phase Flow. Chem. Eng. Commun. 1980, 4, 361380.

(75) Ergun, S. Pressure Drops in Packed Beds. Chem. Eng. Prog. $1952,48,89$.

(76) Montebelli, A.; Visconti, C. G.; Groppi, G.; Tronconi, E.; Ferreira, C.; Kohler, S. Enabling Small-Scale Methanol Synthesis Reactors through the Adoption of Highly Conductive Structured Catalysts. Catal. Today 2013, 215, 176-185.

(77) Twigg, M. V.; Spencer, M. S. Deactivation of Supported Copper Metal Catalysts for Hydrogenation Reactions. Appl. Catal., A 2001, 212, 161-174.

(78) Fichtl, M. B.; Schlereth, D.; Jacobsen, N.; Kasatkin, I.; Schumann, J.; Behrens, M.; Schlögl, R.; Hinrichsen, O. Kinetics of Deactivation on $\mathrm{Cu} / \mathrm{ZnO} / \mathrm{Al}_{2} \mathrm{O}_{3}$ Methanol Synthesis Catalysts. Appl. Catal., A 2015, 502, 262-270.

(79) Martínez, I.; Kulakova, V.; Grasa, G.; Murillo, R. Experimental Investigation on Sorption Enhanced Gasification (SEG) of Biomass in a Fluidized Bed Reactor for Producing a Tailored Syngas. Fuel 2020, 259, No. 116252.

(80) van Kampen, J.; Boon, J.; van Berkel, F.; Vente, J.; van Sint Annaland, M. Steam Separation Enhanced Reactions: Review and Outlook. Chem. Eng. J. 2019, 374, 1286-1303.

(81) van Kampen, J.; Boon, J.; Vente, J.; van Sint Annaland, M. Sorption Enhanced Dimethyl Ether Synthesis for High Efficiency Carbon Conversion: Modelling and Cycle Design. J. $\mathrm{CO}_{2}$ Util. 2020, 37, 295-308. 